This PDF is a selection from an out-of-print volume from the National Bureau of Economic Research

Volume Title: The Role of Direct and Indirect Taxes in the Federal Reserve System

Volume Author/Editor: NBER and The Brookings Institution

Volume Publisher: Princeton University Press

Volume ISBN: 0-87014-469-3

Volume URL: http://www.nber.org/books/unkn64-4

Publication Date: 1964

Chapter Title: Taxation, Resource Allocation, and Welfare

Chapter Author: Arnold Harberger

Chapter URL: http://www.nber.org/chapters/c1873

Chapter pages in book: (p. 25 - 80) 


\title{
Taxation, Resource Allocation, and Welfare
}

\author{
ARNOLD C. HARBERGER
}

\section{UNIVERSITY OF CHICAGO}

\section{Introduction ${ }^{1}$}

DURING the past decade the traditional solution to the issue of direct vs. indirect taxation has been subjected to serious challenge. Whereas earlier the theoretical superiority of direct over indirect taxation was accepted as virtually axiomatic, now it must be regarded as something that cannot be "proved," and that in principle has to be investigated for each particular case. The traditional case for direct taxation rested on its alleged "neutrality" among the alternatives open to consumers. Whereas an indirect tax on one item of consumption made that item artificially expensive to consumers, relative to other goods, and thus consumers were faced with relative prices that did not reflect the relative marginal costs of production of different goods, an income tax was generally held to be free of this defect. The income tax, it was held, was similar to a system of excise taxes striking all commodities with an equal percentage tax rate. Whatever might be the ratios between the marginal costs of producing different goods, the same ratios would (under competition) apply to the prices facing consumers. Marginal rates of substitution in consumption (given by the ratios of gross-of-tax prices between pairs of goods) would therefore be equal to marginal rates of substitution in production (given by the corresponding ratios of net-of-tax prices).

Many economists realized, long before 1951, that this proposition

1 This introductory section is meant to serve, in addition to the usual functions of an introduction, as a guide to readers who might otherwise be put off by the amount of mathematics that appears in the main body of the paper. The principal motivation for and conclusions from each section are set out here in nonmathematical terms, so that readers may skip any offending section of the main text without substantial loss of continuity. For the further guidance of readers, let me here point out that Section IV contains the most mathematical manipulation, and can be skipped with the aid of the summary in the introduction without serious loss. Section II, on the other hand, develops the fundamental framework that is used throughout the paper. Skipping this section therefore entails substantial loss of content. I have tried, in Section II, to develop the basic argument with the aid of graphical analysis, so as to ease the burden on less mathematically oriented readers, and $I$ hope, accordingly, that most readers will be able to work through the derivations presented there. In comparison with Sections II and IV, the remaining sections contain only a modest amount of mathematical manipulation. 
would have to be modified in a situation in which the supply of labor was other than completely inelastic. But the extent of the required modification was not appreciated. In point of fact, the required modification is so great that it destroys any theoretical presumption of the superiority of direct over indirect taxation. This was pointed out by Little in his fundamental paper written in $1951 .{ }^{2}$ He presented a simple example in which labor was the only factor of production and in which there were only three "goods": say, bread, wine, and leisure. In this case, an excise tax on wine would distort the choices between wine and bread and between wine and leisure, but would leave the choice between bread and leisure undistorted. Similarly, an excise tax on bread would distort the choices between bread and wine and between bread and leisure, but would leave the choice between wine and leisure undistorted. However, an income tax (interpreted as an equal-rate excise tax on both bread and wine) would distort the choices between bread and leisure and between wine and leisure, leaving the choice between bread and wine undistorted. Each of the three cases distorts two of the three possible choices, while leaving the third choice undistorted. There is thus no qualitative difference between the nature of the effect of direct as against indirect taxation. Any preference for direct taxation over indirect must therefore be based on quantitative rather than qualitative comparisons, or else on grounds (like equity or political feasibility) that are not strictly economic.

This challenge to the traditional preference for direct taxation provides the focus for most of the present paper. Once Little's argument is appreciated, we can no longer resolve the issue by saying that distortions are present in the indirect-tax case but absent in the direct-tax case. We must recognize that distortions are present in both cases, obtain relevant measures of their effects, and then compare these measures. The relevant measure, in this case, is the cost to the economy of the inefficiencies resulting from tax-induced distortions of choices. This cost, which I like to call the welfare cost of a tax system, has traditionally been labeled the "excess burden" of taxation.

Section II of the paper is an attempt to expound the principles of measuring the welfare costs of a set of taxes in a case where all goods are produced at constant cost. The case chosen is a particularly simple one, because, with the simplification of constant costs, the argument

${ }^{2}$ I. M. D. Little, "Direct Versus Indirect Taxes," Economic Journal, September 1951, pp. 577-584. 
can be carried out in diagrammatic terms. ${ }^{3}$ From this exercise a general expression is derived, from which we can determine the welfare cost of any given pattern of taxes on final goods and services when production is governed by constant costs, when distortions other than taxes are absent, and when the amount of labor supplied by each individual to the market does not vary as a consequence of changes in tax rates.

In Section III we generalize the result of Section II, incorporating the possibility of tax-induced changes in the supply of labor. Thus we face up directly to the problem posed by Little, for the formulation of Section III shows how it is possible to measure the welfare cost of an income tax and to compare this with the welfare costs induced by alternative patterns of indirect taxation. To emphasize the possibility of extracting useful numerical results from analyses of this type, an attempt is made at the conclusion of Section III to estimate the welfare cost of the U.S. personal income tax. It should be borne in mind that this exercise is intended mainly as an example of how the job might be done, and not as a definitive analysis of the U.S. income tax. Among other things, the measurement effort of Section III takes account only of the costs of the personal income tax arising from the labor-leisure choice, and not those that affect occupational choice, investment decisions, etc. Moreover, the measurement is based on crude and scanty evidence of a highly aggregative nature, whereas a more complete analysis would take into account the differential responses of different classes of labor supply to tax incentives (e.g., distinguishing between the effects of taxation on labor-force participation rates of women and men). Finally, the measurement in Section III (as distinct from the theory presented) is based on the assumption that the income tax is the only tax present in the system, or, perhaps more plausibly, on the assumption that the welfare costs of the personal income tax are not altered by the many other taxes that are present in the U.S. system.

In spite of these qualifications, however, I feel that the exercise of Section III provides us with some useful insights. The estimated welfare cost of the U.S. personal income tax is about $\$ 1$ billion per year-hardly a negligible figure. Yet the simplifying assumptions just alluded to probably have the effect of understating the true cost. It is hard indeed, in the light of this result, to hold to the traditional position that the personal income tax is truly neutral.

${ }^{3}$ For a more general mathematical treatment, see my paper, "The Measurement of Waste," American Economic Review, May 1964. 
In Section IV we attempt a direct comparison of the welfare costs of income and excise taxation. This entails nothing more than a straightforward application of the general formulation derived in Section III, but some relevant insights are obtained by carrying out the steps. As the first step in Section IV, we try to find the "best" way of raising a given amount of revenue by commodity taxation. We find, as others ${ }^{4}$ have previously shown, that an income tax (i.e., a tax striking all goods and services other than leisure at an equal rate) will be the "best" way only in very unusual circumstances. If, as seems to be the case in the real world, we cannot tax leisure as such, then the "best" tax system we can achieve under this constraint is one that strikes at higher-thanaverage rates those goods that are complements to or poorer-than-average substitutes for leisure, and that strikes at lower-than-average rates those goods that are better-than-average substitutes for leisure. An income tax is "best," given the constraint that leisure cannot be taxed, only if all goods are equally good substitutes for leisure (i.e., only if a tax on leisure would lead to an equiproportional change in the consumption of each and every good and service).

This conclusion could indeed be shattering to the principle of direct taxation if it meant that the welfare costs of taxation could be greatly lowered by having widely different rates of taxation on different goods and services as against the equal rates implied by income taxation. It does not appear, however, that this is the case. One way of determining the answer to the question just posed is to compare the welfare cost of a particular indirect tax with the welfare cost of an income tax yielding equal revenue. This is the second step taken in Section IV. It recognizes that the relevant substitute for an indirect tax is not "no tax at all" but rather some other manner of obtaining the same yield, and it considers the particular alternative represented by income taxation. The result of this exercise is that, as long as the excise tax in question is not itself a very general tax (striking a large fraction of all goods and thus approaching an income tax in coverage), and as long as the elasticity of demand for the commodity or commodities subject to excise tax is not very small, the substitution of an income tax for the excise tax in question will very likely result in a reduction of welfare cost.

The third step in Section IV attempts to make the preceding compari-

" See Little in Economic Journal, September 1951; W. J. Corlett and D. C. Hague, "Complementarity and the Excess Burden of Taxation," Review of Economic Studies, No. 54, 1953-54, pp. 21-30; J. E. Meade, Trade and Welfare, Vol. II, Mathematical Supplement, London, 1955; R. G. Lipsey and K. Lancaster, "The General Theory of Second Best," Review of Economic Studies, No. 63, 1956-57, pp. 11-32. 
son a bit more realistic. One of the key propositions that emerges from the study of welfare costs in a general-equilibrium framework (such as that taken in this paper) is that the effects of a particular tax depend not only on that tax itself but on the other taxes that are present along with it. The comparison made in step two of Section IV considers an excise tax that is being used as the sole tax in the system, and is replaced by and compared with an income tax of equal yield. In step three of Section IV we alter this comparison, and instead consider an excise tax which, when present, stands side by side with an income tax of a given size. We compare this setup with an alternative one in which the excise tax is taken off and replaced by a sufficient rise in the rate of income tax to produce the same total yield as was previously obtained from the excise and income taxes combined. This comparison is slightly more complicated than that undertaken in step two, but does not greatly alter the conclusion. Broadly speaking, there is still a strong presumption in favor of replacing excise taxation with income taxation, as long as the excise taxation itself is not very general and as long as the taxed commodities do not have very low elasticities of demand. When one comes to consider excise taxes that have very low rates and/or very broad bases, however, the result is no longer so clear. In these cases, considerations of the complementarity (or low substitutability) of an excise-taxed commodity with leisure might weigh the final judgment in favor of retaining the excise tax rather than replacing it by an adjustment of income tax rates. One might say, in short, that the theoretical case in favor of direct taxation has been forced into full retreat by the considerations raised by Little and others in recent years; but that the practical case remains comparatively unscathed, particularly where the excise taxes in question have relatively high rates and do not strike a very high proportion of consumer expenditures.

In Section $\mathrm{V}$ the effects of taxation on saving are considered. The treatment, far briefer than the subject deserves, focuses on the nonneutrality of ordinary income taxation with respect to the saving decision, and on the measurement of the welfare costs engendered by this nonneutrality. It is shown that income taxation has the effect of reducing the rate of saving, when the alternative to the income tax is a consumption tax yielding the same amount each year. A simple formula for estimating the welfare costs of the distortions introduced by income taxation through its influence upon the savings decision is then presented. In terms of this formula, a very rough judgment is reached on the possible order of magnitude of this class of welfare costs in the 
United States economy. Finally, it is suggested that the welfare costs stemming from the differential tax treatment of different kinds of income from capital in the U.S. are likely to be substantially greater than the welfare costs arising from the influence of taxation on the saving decision as such. That is to say, the U.S. economy very likely suffers greater costs from tax-induced misallocations of its given capital stock than from the influence of taxation on the over-all size of that capital stock.

Finally, in Section VI, an effort is made to draw some conclusions from the preceding analysis on the influence of taxation on economic growth. Since previous sections of this paper are concerned mainly with the labor-leisure choice and with the saving decision, the discussion of taxation and growth is focused in these terms. The conclusion is reached that the effects of taxation on the labor-leisure choice have a truly negligible effect on the economy's rate of growth, but that the effect of taxation on the saving decision may reduce the economy's annual rate of growth by as much as one-tenth or two-tenths of a percentage point. For those who are surprised by the small effect of taxation via the saving decision, Section VI reviews the evidence supporting this result.

To set the stage for the treatment which follows, I should first like to discuss certain key assumptions that will be used throughout this paper.

1. It is assumed that, under any two situations being compared, the economy's productive resources are fully employed. This assumption is the conventional one in studies of the allocative effects of taxation. The resource allocation question can be framed as "how will our resources be used?" as distinct from the alternative income-and-employment question of "will some of our resources be idle?" The effect of this assumption, for the problems treated in this paper, is to restrict the set of possible resource allocations to that determined by the production frontier of the economy. Thus in Figure 1, the alternative bundles of goods $X_{1}$ and $X_{2}$ produced in any of the cases to be compared will lie somewhere along the production frontier $A B$. A production point like $C$, indicating that the economy is not producing up to its potential, is ruled out by assumption.

2. It is assumed that, under any two alternative taxes to be compared, the government will obtain just that amount of purchasing power needed to buy a given bundle of goods. One need not belabor the point that if we are to discuss the effects of a given tax on resource allocation, we must implicitly or explicitly compare the situation in which that tax 


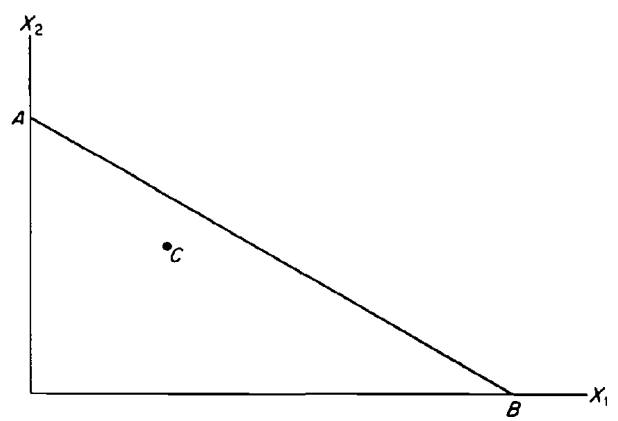

Figure 1

exists with some alternative situation. Once this is recognized, we have a variety of choices. We can compare the "tax situation" with a "no-tax situation" or with any possible combination of alternative taxes. But this is not the worst of it. If the total revenues of the government have different purchasing power in the cases being compared, we must either have differing amounts of deficit or surplus in the two cases, or differing amounts of government expenditure. If surpluses or deficits differ, deflationary or inflationary forces are set in motion by the tax change, and we are taken from the realm of allocative theory into that of income-andemployment analysis. If government expenditures differ in the two cases, we must inquire into how the government spends its added revenue or reduces its prior expenditures. This opens a Pandora's box of possibilities in an analysis of resource allocation effects, for there are an infinity of ways in which the government could allocate any increase or reduction in expenditures. To avoid having to guess what the government would do with its money, we simply assume that the government would do the same thing in both the situations being compared. This, together with the previous assumption, enables us to conceive of a "consumption frontier" or, perhaps better, a private-sector expenditures frontier, obtained by deducting the fixed pattern of government purchases from the economy's production frontier. Thus, in Figure 2, every point on the "consumption frontier" $C D$ is obtained by deducting the fixed amounts of government purchases $G_{1}$ and $G_{2}$ from the corresponding point on the production frontier $A B$. As long as the government is getting the bundle $\left(G_{1}, G_{2}\right)$ of $X_{1}$ and $X_{2}$, and as long as the economy is operating on the production frontier, production will take place somewhere within the segment $E F$ of $A B$, and the "consumption" of the private sector must lie somewhere along $C D$ in any two cases being compared.

3 . It is assumed that the changes in output dictated by the changes 


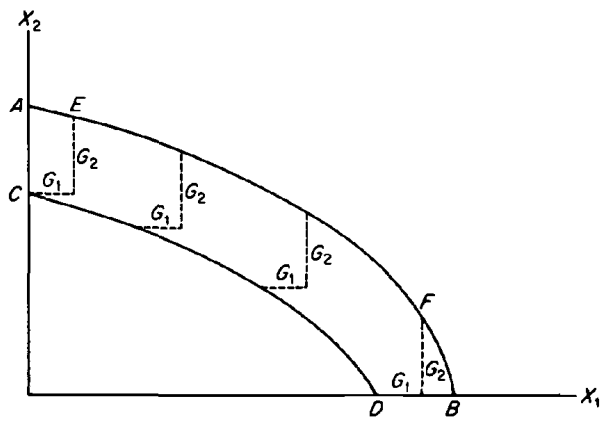

Figure 2

in tax policy being considered are accomplished at (approximately) constant unit cost. Taken strictly, this assumption requires that the production frontier be linear within the relevant range. Taken less strictly, it requires only that the production frontier be reasonably well approximated by a linear function within the relevant range. I am prepared to argue that this is likely to be the case for the changes in output which would be induced by plausible changes in the taxes now in force in the United States. But I must confess that this assumption is mainly dictated by considerations of convenience. The mathematical parts of subsequent sections of this paper would be greatly complicated if the assumption of constant costs were abandoned, and yet the principal qualitative conclusions of the analysis would be unaffected.

4. It is assumed that, where "welfare costs" are being measured, the tax setup being considered has as its alternative a tax system of similar over-all incidence. The alternatives being compared are assumed to have similar over-all incidence in order to isolate the allocative effects of taxation from its redistributive effects. For example, if we are concerned with the effects of eliminating a tax on jewelry, whose incidence among income brackets is as indicated in column 1 of Table 1 , we might so adjust income-tax rates as to increase income-tax collections from each bracket by approximately these same amounts. Thus if income-tax collections, by bracket, were originally as given by column 2 of Table 1 , we would consider an income tax collecting the amounts given in column 3 to be an appropriate alternative to the tax setup given by columns 1 and 2 .

This is not to say that the real alternatives faced by policy-makers are likely to be as neatly comparable as those in Table 1. But if the practical alternative (say, 3) to alternative 1 is an income tax which is different in its incidence from alternative 2 , we would simply analyze the move 
TAXATION, RESOURCE ALLOCATION, WELFARE

TABLE 1

TAX COLLECTIONS BY INCOME BRACKET, PER TAXPAYER

\begin{tabular}{|c|c|c|c|}
\hline \multirow[b]{2}{*}{$\begin{array}{c}\text { Income } \\
\text { Brackets }\end{array}$} & \multicolumn{2}{|c|}{ Alternative 1} & \multirow{2}{*}{ 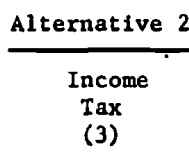 } \\
\hline & $\begin{array}{c}\text { Exclse Tax } \\
\text { on Jewelry } \\
\text { (1) }\end{array}$ & $\begin{array}{l}\text { Income } \\
\text { Tax } \\
(2)\end{array}$ & \\
\hline 1 & 20 & 50 & 70 \\
\hline 2 & 30 & 100 & 130 \\
\hline 3 & 40 & 200 & 240 \\
\hline 4 & 50 & 400 & 450 \\
\hline 5 & 60 & 1,000 & 1,060 \\
\hline
\end{tabular}

from 1 to 3 as the sum of a move from 1 to 2 , which we would evaluate using purely allocative criteria, ${ }^{5}$ plus a move from 2 to 3 , which we would evaluate using purely distributive criteria.

\section{Measuring the Welfare Cost of Excise Taxes}

In this section, we begin by outlining the "textbook" treatment of welfare cost in the simplest terms, and proceed to extend the analysis to more complicated cases. The textbook case is illustrated in Figure 3.

We are to compare a situation in which there is an excise tax of $\$ 1$ per unit of $X\left(X=X_{4} ; P_{x}=\$ 2.00\right)$ with a situation in which this tax does not exist, but in which the government is raising equivalent revenue by an income tax $\left(X=X_{0} ; P_{x}=\$ 1\right)$. It is important to recognize at the outset that $D_{x}$ is defined as holding government revenues constant. Thus at $P_{4}$ we have government revenues equal to $(\$ 1)\left(X_{4}\right)$, all obtained from the excise tax on $X$. As we move to $P_{3}$, the excise tax must be lowered to $\$ .75$, and government revenues from the excise tax alone are only $(\$ .75)\left(X_{3}\right)$. However, since government revenues must be constant all along the curve, there must be, at point $P_{3}$, income taxation to yield $(\$ 1)\left(X_{4}\right)-(\$ .75)\left(X_{3}\right)$. At $P_{2}$ income taxes must yield $(\$ 1)\left(X_{4}\right)-$

5 Strictly speaking, one can eliminate distributive criteria in evaluating the move from 1 to 2 only when each and every individual bears the same burden of tax in both cases. Actually, the move from 1 to 2 as described above would entail some redistribution of income in favor of jewelry purchasers and away from those who do not purchase jewelry or purchase only small amounts relative to the average of their income bracket. But this redistribution is entirely within income brackets, and thus is not likely in itself to significantly alter the pattern of demand. Moreover, if the equal treatment of equals is accepted as a goal of tax policy, one would have to regard the move from 1 to 2 as having beneficial effects on distribution (differing tastes of people with similar incomes should not make these people "unequal"). Thus, as long as there would be an allocative gain on this move, we can consider it as being slightly reinforced by distributive considerations. 

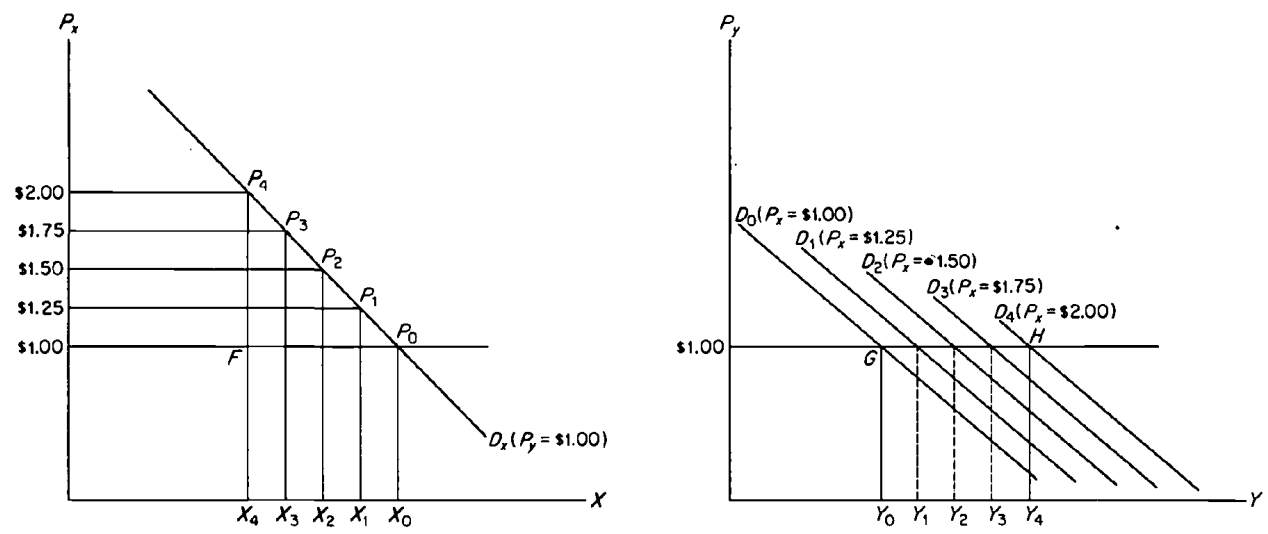

Figure 3

$(\$ .50)\left(X_{2}\right)$; at $P_{1}$ they must yield $(\$ 1)\left(X_{4}\right)-(\$ .25)\left(X_{1}\right)$; and at $P_{0}$ they must yield $(\$ 1)\left(X_{4}\right)$.

The simplest exposition of the measurement of the welfare cost of excise taxation can be made by looking only at the left-hand diagram in Figure 3. As between the situation $\left(X_{0}, P_{0}\right)$ and the situation $\left(X_{4}, P_{4}\right)$, consumers have given up $\left(X_{0}-X_{4}\right)$ units of the good $X$. The value placed by them on the first unit given up was $\$ 1$, but subsequent units had higher values. If we think of the tax being gradually raised from zero to $\$ 1$, this is clearly evident. When the tax is raised from zero to $\$ .01$, the units of $X$ given up have values between $\$ 1$ and $\$ 1.01$; when the tax is raised from $\$ .01$ to $\$ .02$, the units of $X$ given up have values between $\$ 1.01$ and $\$ 1.02$. Finally, when the tax is raised from $\$ .99$ to $\$ 1.00$, consumers value the units of $X$ given up at between $\$ 1.99$ and $\$ 2.00$. The sum total of the value placed by consumers on all the $X$ they have given up in the process of raising the tax from zero to $\$ 1$ can be measured by the area $X_{0} P_{0} P_{4} X_{4}$.

But in the process of demanding less $X$ as a consequence of the tax, consumers have released resources from industry $X$ and increased their demand for other goods $(Y)$. The measure $X_{0} P_{0} P_{4} X_{4}$ therefore overstates their real loss; from it we have to deduct the value of the extra $Y$ they consume in the excise-tax case. Where there is no tax (or other divergence between the value placed by consumers on the marginal product of productive factors and the rewards received by those factors) on $Y$, the value to consumers of the extra $Y$ they have in case $\left(X_{4}, P_{4}\right)$ compared to case $\left(X_{0}, P_{0}\right)$ can simply be measured by the area $X_{0} P_{0} F X_{4}$. This represents the amount which was originally paid in industry $X$ to the factors transferred to $Y$ as a result of the tax. Deducting $X_{0} P_{0} F X_{4}$ 
from $X_{0} P_{0} P_{4} X_{4}$ leaves the triangle $P_{0} P_{4} F$ as the measure of the welfare cost or "excess burden" of a $\$ 1$ per unit excise tax on $X$.

The right-hand diagram in Figure 3 may help readers to verify that $X_{0} P_{0} F X_{4}$ does in fact measure the value to consumers of the extra $Y$ they demand as a consequence of the tax on $X$. Again, considering a sequence in which the tax on $X$ is gradually raised from zero to $\$ 1$, we have first a slight displacement of the demand curve for $Y$ as the price of $X$ is raised from $\$ 1.00$ to $\$ 1.01$, and a little extra $Y$ is bought at the price of $\$ 1.00$. As the price of $X$ is raised from $\$ 1.01$ to $\$ 1.02$, another slight displacement of the demand curve for $Y$ occurs, and again a little extra $Y$ is bought at the price of $\$ 1$. Summing up the values to consumers of the successive increments to $Y$ generated by raising $P_{x}$ all the way to $\$ 2.00$, we obtain the area $Y_{0} G H Y_{4}$, which is equal to the area $X_{0} P_{0} F X_{4}$ in the left-hand diagram.

There is no contribution to welfare cost (corresponding to the triangle $P_{0} P_{4} F$ ) coming from the market for $Y$ because, by assumption, no distortions are present in that market. The resource cost of an extra unit of $Y$ is $\$ 1.00$, and the moment consumers find that it is worth $\$ 1$ to buy an extra unit of $Y$, they can freely do so. Thus the value to consumers of each extra unit of $Y$ they take is equal to the price they pay for it.

To summarize the result obtained so far, when a $\operatorname{tax}$ on $X$ of $T_{x}$ per unit is the only distortion present, the welfare cost of that tax can be measured by $-\frac{1}{2} T_{x} \Delta X$, where $\Delta X$ is the change in the consumption of $X$ induced by the tax. If we define $t_{x}\left(=T_{x} / P_{x 0}\right)$ as the percentage rate of tax, we can note that (with constant costs) it also represents the percentage change in the price of $X$. We then can derive $\Delta X=\eta_{x x} X t_{x}$, where $\eta_{x x}$ is the own-price elasticity of demand for $X$. Substituting this expression for $\Delta X$, and $P_{x 0} t_{x}$ for $T_{x}$ in the cost measure $\left(-\frac{1}{2} T_{x} \Delta X\right)$, we obtain as an alternative expression for the welfare cost of an excise tax $-\frac{1}{2} X P_{x 0} \eta_{x x} t_{x}^{2}$. This expresses the welfare cost of a tax in terms of $\left(X P_{x 0}\right)$, the total net-of-tax receipts from sales of the product in question; $\eta_{x x}$, the own-price elasticity of demand for the product (a negative number); and $t_{x}$, the effective percentage rate of tax. Since the total tax yield, $R_{x}$, can be expressed as $X P_{x 0} t_{x}$, we can also express the welfare cost of the tax as $-\frac{1}{2} R_{x} \eta_{x x} t_{x}$. Since data on $R_{x}$ and $t_{x}$ are usually available for any existing tax, only $\eta_{x x}$ need be estimated to obtain a measure of the welfare cost of such a tax.

In the course of this paper we shall show that this simple textbook measure of welfare cost is not a bad approximation in the cases of most existing taxes. But in order to reach this conclusion, we must modify 
the above analysis to take account of the main ways in which the realworld situation diverges from that depicted in Figure 3.

By far the most disquieting assumption underlying Figure 3 and the analysis of it is the assumption that no excise taxes or other distortions exist in the "rest" of the economy (industry $Y$ ). It is possible, however, to modify the analysis so as to avoid making this assumption.

Figure 4 differs from Figure 3 only in that the initial price of $Y$ is taken
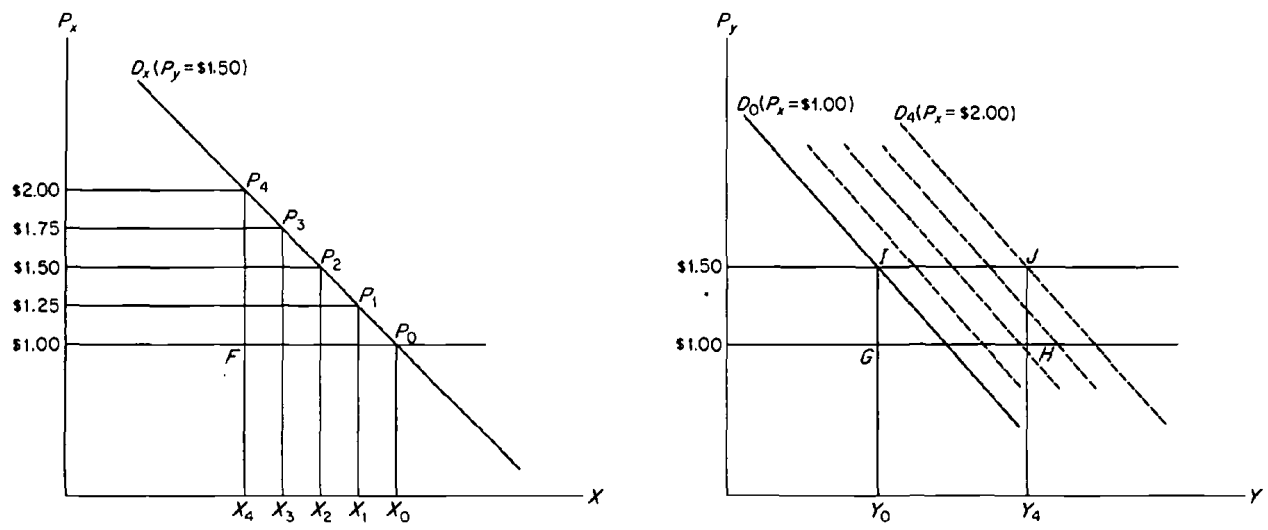

Figure 4

to be $\$ 1.50$, consisting of a unit cost of $\$ 1$ plus a tax of $\$ .50$ per unit. Once again, as we envision the $\operatorname{tax}$ on $X$ being raised in small steps from 0 to $\$ 1.00$ per unit, we obtain the area $X_{0} P_{0} P_{4} X_{4}$ as measuring the value to consumers of the $\left(X_{0}-X_{4}\right)$ units of $X$ that they are induced to forego as a consequence of the tax.

The difference between this and the earlier case appears in the righthand diagram of Figure 4. Whereas, in Figure 3, consumers were initially paying $\$ 1$ per unit of $Y$, and continued paying that price after the tax was imposed on $X$, now, in Figure 4, consumers are initially paying $\$ 1.50$ per unit of $Y$, and continue to pay that price throughout the exercise. Hence the value to consumers of the extra $Y$ that they are induced to consume by the tax on $X$ is $Y_{0} I J Y_{4}$, rather than $Y_{0} G H Y_{4}$. In the present case, therefore, the net change in the welfare of consumers as a result of the tax on $X$ is measured by the difference between a loss of $X_{0} P_{0} P_{4} X_{4}$ (on account of $\left[X_{0}-X_{4}\right]$ units of $X$ being foregone), and a gain of $Y_{0} I J Y_{4}$ (on account of $\left[Y_{4}-Y_{0}\right]$ more units of $Y$ being consumed). Since the areas $X_{0} P_{0} F X_{4}$ and $Y_{0} G H Y_{4}$ are equal as before (the cost of production of the addition to $Y$ is the same as the reduction in production costs of $X)$, the net loss in the welfare of consumers can be measured by $P_{0} P_{4} F$ minus $G I J H$. Since $G I J H=\left(t_{y}\right) \times\left(Y_{0} G H Y_{4}\right)$, and 
$Y_{0} G H Y_{4}=X_{0} P F X_{4}$, we can express $G I J H=\left(t_{y}\right) \times\left(X_{0} P F X_{4}\right)=$ $t_{y} P_{x 0} \Delta X$. This, in turn, can be expressed as $G I J H=t_{y} X P_{x 0} \eta_{x x} t_{x}$. Now $P_{0} P_{4} F=-\frac{1}{2} X P_{x 0} \eta_{x x} t_{x}^{2}$, so that the net loss in welfare from placing a tax of $t_{x}$ on $X$ in the presence of an already existing tax of $t_{y}$ on $Y$ can be expressed as:

$$
-\frac{1}{2} X P_{x 0} t_{x} \eta_{x x}\left[t_{x}-2 t_{y}\right]=-\frac{1}{2} R_{x} \eta_{x x}\left[t_{x}-2 t_{y}\right] .
$$

From this it can be seen that there is a clear gain from placing a tax on $X$ equal to the pre-existing tax on $Y$. The expression $-\frac{1}{2} R_{x} \eta_{x x}$ is always positive, and the expression $t_{x}-2 t_{y}$ is negative when $t_{x}=t_{y}$. Therefore the "cost" of moving $t_{x}$ from zero to $t_{y}$ is negative, indicating a gain in welfare.

In the example chosen for Figure $4, t_{x}$ was set at twice $t_{y}$. Thus the expression above indicates that there is no gain or loss in welfare. This can be verified by looking at Figure 4 . The loss measured by the triangle $P_{0} P_{4} F$ is just counterbalanced by the gain measured by the rectangle GIJH. ${ }^{6}$

The extension of this result to the case of three or more commodities is self-evident. In Figure 5, we assume that a tax of $\$ .50$ per unit on $X_{2}$,
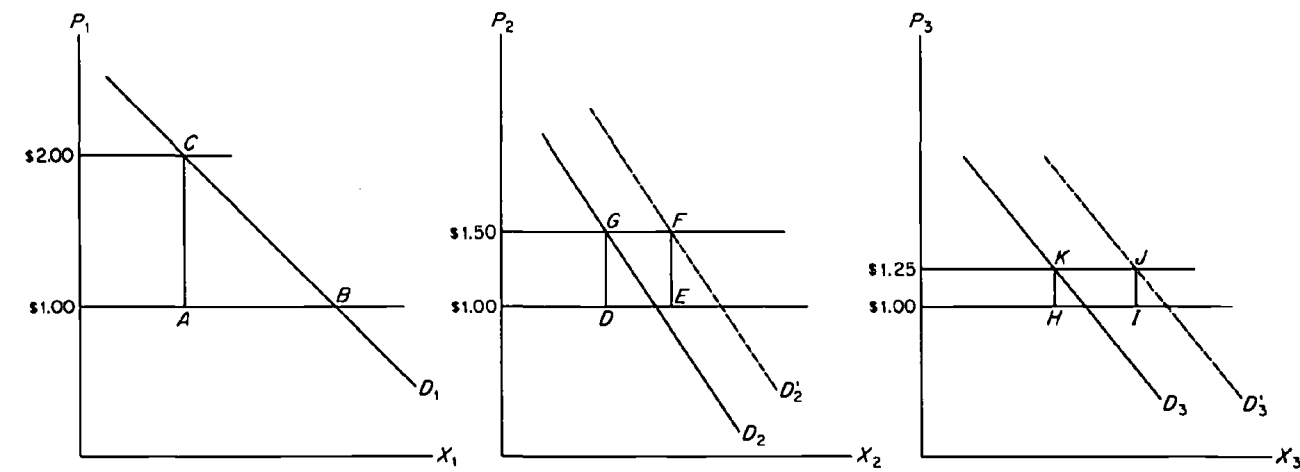

Figure 5

and one of $\$ .25$ per unit on $X_{3}$ were already in existence before a tax of $\$ 1.00$ per unit was levied on $X_{1}$. The reduction in welfare of consumers as a consequence of the tax on $X_{1}$ is measured by the area $A B C$ minus the sum of the areas DEFG and HIJK.

We can now turn to the derivation of a general expression for the welfare cost of a set of excise taxes. Assume there are three commodities, $X_{1}, X_{2}, X_{3}$, all of which are taxed. The welfare cost of the whole set

${ }^{6}$ Both the rectangle and the triangle have equal bases, but the height of the triangle is just twice that of the rectangle. 
of taxes can be measured by taking first the welfare cost of a tax on $X_{1}$, with no other taxes in existence; adding to this the addition to the welfare cost obtained by imposing a tax on $X_{2}$, given that the tax on $X_{1}$ already exists; and finally adding the increment to the welfare cost incurred by imposing a tax on $X_{3}$, given that the taxes on $X_{1}$ and $X_{2}$ already exist.

Since the effects of the taxes will be analyzed in three steps, let us denote by $\Delta_{1}$ those changes taking place in the first step (when a tax is imposed on $X_{1}$ ), and by $\Delta_{2}$ and $\Delta_{3}$, respectively, those changes taking place in the second and third steps.

When a tax of $T_{1}$ is imposed on $X_{1}$, with no taxes on $X_{2}$ and $X_{3}$, the welfare cost is simply

$$
-\frac{1}{2} T_{1} \Delta_{1} X_{1}
$$

i.e., the triangle $P_{0} P_{4} F$ in Figure 3 . When a tax of $T_{2}$ is imposed on $X_{2}$ in the presence of a tax of $T_{1}$ on $X_{1}$, the addition to welfare cost is

$$
-\frac{1}{2} T_{2} \Delta_{2} X_{2}-T_{1} \Delta_{2} X_{1} \text {. }
$$

The first component is the triangle under the demand curve for $X_{2}$ (corresponding to $A B C$ in Figure 5), and the second is the offset (corresponding to $D E F G$ in Figure 5) arising from the fact that a tax on $X_{1}$ already exists. (There is no offset corresponding to HIJK in Figure 5, because at this step we have not yet imposed any tax on $X_{3}$.)

When a tax of $T_{3}$ is imposed on $X_{3}$ in the presence of taxes of $T_{1}$ and $T_{2}$ on $X_{1}$ and $X_{2}$, the addition to welfare cost is

$$
-\frac{1}{2} T_{3} \Delta_{3} X_{3}-T_{1} \Delta_{3} X_{1}-T_{2} \Delta_{3} X_{2} .
$$

The sum of $(a)+(b)+(c)$ gives us the welfare cost of the set of taxes $\left(T_{1}, T_{2}, T_{3}\right)$ taken together. Let me here introduce $S_{i j}$ as a general notation for $\partial X_{1} / \partial P_{j}$, defined to include just the substitution effect. We can then write:

$$
\begin{aligned}
& \Delta_{1} X_{1}=\frac{\partial X_{1}}{\partial P_{1}} T_{1}=S_{11} T_{1} \\
& \Delta_{2} X_{1}=\frac{\partial X_{1}}{\partial P_{2}} T_{2}=S_{12} T_{2} \\
& \Delta_{3} X_{1}=\frac{\partial X_{1}}{\partial P_{3}} T_{3}=S_{13} T_{3} \\
& \Delta_{2} X_{2}=\frac{\partial X_{2}}{\partial P_{2}} T_{2}=S_{22} T_{2} \\
& \Delta_{3} X_{2}=\frac{\partial X_{2}}{\partial P_{3}} T_{3}=S_{23} T_{3} \\
& \Delta_{3} X_{3}=\frac{\partial X_{3}}{\partial P_{3}} T_{3}=S_{33} T_{3} .
\end{aligned}
$$


Substituting into (a), (b), and (c), and summing, we obtain as the expression for the welfare cost of the set of taxes

$$
-\frac{1}{2} S_{11} T_{1}^{2}-\frac{1}{2} S_{22} T_{2}^{2}-\frac{1}{2} S_{33} T_{3}^{2}-S_{12} T_{1} T_{2}-S_{13} T_{1} T_{3}-S_{23} T_{2} T_{3},
$$

or alternatively

$$
-\frac{1}{2}\left[S_{11} T_{1}^{2}+S_{22} T_{2}^{2}+S_{33} T_{3}^{2}+2 S_{12} T_{1} T_{2}+2 S_{13} T_{1} T_{3}+2 S_{23} T_{2} T_{3}\right] .
$$

Recognizing that $S_{i j}=S_{j i}{ }^{7}$ we can express this as

$$
-\frac{1}{2} \sum_{i} \sum_{j} S_{i j} T_{i} T_{j}
$$

This is one of three fundamental forms in which the welfare cost of a set of taxes may be written. The second fundamental form may be derived by breaking up (a) $+(\mathrm{b})+(\mathrm{c})$ into expressions reflecting changes in the quantity of each commodity. Thus we have, from commodity 1 ,

$$
-\frac{1}{2} T_{1} \Delta_{1} X_{1}-T_{1} \Delta_{2} X_{1}-T_{1} \Delta_{3} X_{1} \text {. }
$$

Denoting the total change in $X_{1}$ by $\Delta X_{1}=\Delta_{1} X_{1}+\Delta_{2} X_{1}+\Delta_{3} X_{1}$, we may express this as

$$
-\frac{1}{2} T_{1} \Delta X_{1}-\frac{1}{2} T_{1} \Delta_{2} X_{1}-\frac{1}{2} T_{1} \Delta_{3} X_{1}
$$

Likewise, we have for commodity 2 ,

$$
-\frac{1}{2} T_{2} \Delta_{2} X_{2}-T_{2} \Delta_{3} X_{2}
$$

which we can express as

$$
-\frac{1}{2} T_{2} \Delta X_{2}-\frac{1}{2} T_{2} \Delta_{3} X_{2}+\frac{1}{2} T_{2} \Delta_{1} X_{2} .
$$

Finally, we have for commodity 3 ,

which can be expressed as

$$
-\frac{1}{2} T_{3} \Delta_{3} X_{3}
$$

$$
-\frac{1}{2} T_{3} \Delta X_{3}+\frac{1}{2} T_{3} \Delta_{1} X_{3}+\frac{1}{2} T_{3} \Delta_{2} X_{3} .
$$

The sum of $\left(a^{\prime}\right)+\left(b^{\prime}\right)+\left(c^{\prime}\right)$ will give us the welfare cost of the set of taxes under consideration. But six of the nine terms in the sum cancel

7 The equality of $\frac{\partial X_{i}}{\partial P_{j}}$ with $\frac{\partial X_{j}}{\partial P_{i}}$ is one of the fundamental properties of demand relationships reflecting the substitution effect only. See John R. Hicks, Value and Capital, p. 311. Hicks uses the notation $X_{i j}$ to refer to what we have called $S_{i j}$. It is not easy to give an intuitive interpretation of why $S_{i j}$ should equal $S_{j i}$. The best I can do is as follows: If the prices of both $X_{1}$ and $X_{2}$ rise by 1 per cent, no substitution effects will take place between them. This means that the substitution effect between $X_{1}$ and $X_{2}$ which takes place because of a rise of 1 per cent in $P_{1}$ is annulled by the substitution effect taking place as a result of a 1 per cent rise in $\boldsymbol{P}_{2}$. Now the transfer of purchasing power from $X_{1}$ to $X_{2}$ taking place as a result of a 1 per cent rise in the price of $X_{1}$ is given by $P_{2}\left(\partial X_{2} / \partial P_{1}\right) P_{1}$. And the transfer of purchasing power from $X_{2}$ to $X_{1}$ resulting from a 1 per cent rise in the price of $X_{2}$ is equal to $P_{1}\left(\partial X_{1} / \partial P_{2}\right) P_{2}$. In order for the second effect to annul the first, $\left(\partial X_{2} / \partial P_{1}\right)$ must equal $\left(\partial X_{1} / \partial P_{2}\right)$, or $S_{21}=S_{12}$. 
each other out. Consider the two terms $-\frac{1}{2} T_{1} \Delta_{2} X_{1}+\frac{1}{2} T_{2} \Delta_{1} X_{2}$. We know that $\Delta_{2} X_{1}=S_{12} T_{2}$, and $\Delta_{1} X_{2}=S_{21} T_{1}$. Thus these terms can be expressed as

$$
-\frac{1}{2} T_{1} T_{2} S_{12}+\frac{1}{2} T_{2} T_{1} S_{21}
$$

which must equal zero since $S_{12}=S_{21}$. By the same token, each of the pairs of terms $\left(-\frac{1}{2} T_{1} \Delta_{3} X_{1}+\frac{1}{2} T_{3} \Delta_{1} X_{3}\right)$ and $\left(-\frac{1}{2} T_{2} \Delta_{3} X_{2}+\frac{1}{2} T_{3} \Delta_{2} X_{3}\right)$ must equal zero. Thus the second fundamental expression for welfare cost reduces to

$$
-\frac{1}{2} T_{1} \Delta X_{1}-\frac{1}{2} T_{2} \Delta X_{2}-\frac{1}{2} T_{3} \Delta X_{3}=-\frac{1}{2} \sum_{i} T_{i} \Delta X_{i}
$$

To derive the third form of the expression for welfare cost, consider the expression (first form), letting $C_{i}=$ unit cost of commodity $i, t_{i}$ the percentage rate of tax on commodity $i$, and $C_{i} t_{i}=T_{i}$, the unit tax on $i$, $-\frac{1}{2}\left[C_{1}^{2} S_{11} t_{1}^{2}+C_{2}^{2} S_{22} t_{2}^{2}+C_{3}^{2} S_{33} t_{3}^{2}\right.$

$$
\left.+2 C_{1} C_{2} S_{12} t_{1} t_{2}+2 C_{1} C_{3} S_{13} t_{1} t_{3}+2 C_{2} C_{3} S_{23} t_{2} t_{3}\right] .
$$

Now we make use of the well-known relationship among the $S_{i j}$, $\sum_{i} C_{i} S_{i j}=\sum C_{j} S_{j i}=0 .{ }^{8}$

$$
\begin{aligned}
C_{1}^{2} S_{11} t_{1}^{2} & =-C_{1} C_{2} S_{12} t_{1}^{2}-C_{1} C_{3} S_{13} t_{1}^{2} \\
C_{2}^{2} S_{22} t_{2}^{2} & =-C_{1} C_{2} S_{12} t_{2}^{2}-C_{2} C_{3} S_{23} t_{2}^{2} \\
C_{3}^{2} S_{33} t_{3}^{2} & =-C_{1} C_{3} S_{13} t_{3}^{2}-C_{2} C_{3} S_{23} t_{3}^{2} \\
2 C_{1} C_{3} S_{13} t_{1} t_{3} & =2 C_{1} C_{3} S_{13} t_{1} t_{3} \\
2 C_{2} C_{3} S_{23} t_{2} t_{3} & =2 C_{2} C_{3} S_{23} t_{2} t_{3} \\
2 C_{1} C_{2} S_{12} t_{1} t_{2} & =2 C_{1} C_{2} S_{12} t_{1} t_{2} .
\end{aligned}
$$

${ }^{8}$ This relationship can be interpreted intuitively in two ways. First, when there is a linear constraint of the form $\Sigma_{i} C_{i} X_{i}=K$, then, as long as the constraint is satisfied, $\sum_{i} C_{i} \frac{\partial X_{i}}{\partial z}=0$, for any definition of $z$. Thus setting $z=P_{j}$, we have $\Sigma C_{i} \frac{\partial X_{i}}{\partial P_{j}}=0$, or $\sum_{i} C_{i} S_{i j}=0$. Alternatively, we may start from the general property of substitution effects that "only relative prices count." This says that the effect on $X_{i}$ of a 1 per cent rise in its price would be annulled by a 1 per cent rise in all other prices. The effect on $X_{i}$ of a 1 per cent rise in its own price is given by

$$
\frac{\partial X_{i}}{\partial P_{i}} P_{i}=S_{i i} P_{i}
$$

The effect on $X_{i}$ of a 1 per cent rise in the price of $X_{j}$ is $\frac{\partial X_{i}}{\partial P_{j}} P_{j}=S_{i j} P_{j}$. The effect on $X_{i}$ of a 1 per cent rise in all other prices is $\underset{j \neq i}{\sum} S_{i j} P_{j}$. In order for the first effect, $S_{i i} P_{i}$, to be offset by the second, we must have

$$
S_{i i} P_{i}+\underset{j \neq i}{\sum} S_{i j} P_{j}=0, \quad \text { or } \underset{j}{\sum} S_{i j} P_{j}=0 \text {. }
$$

Now if, as we do when measuring the total welfare cost of a set of distortions, we are measuring this cost as against an undistorted initial situation, we can characterize the undistorted situation as one in which, for all $j, P_{j}=k C_{j}$; that is, prices bear the same relationship to unit costs for all commodities. Thus we have $\underset{j}{\Sigma} S_{i j} k C_{j}=0$, or $\sum_{j} S_{i j} C_{j}=0$. See Hicks, Value and Capital, pp. 310-311. 
On the left-hand side of the equalities in the six equations above, we have the terms appearing within the bracket in the expression for welfare cost (first form). On the right-hand side, we have the expressions which will be used in deriving the third form. To do so, we simply collect terms in $S_{12}, S_{13}$, and $S_{23}$, yielding

$$
\begin{aligned}
& -S_{12} C_{1} C_{2}\left[t_{1}^{2}-2 t_{1} t_{2}+t_{2}^{2}\right]=-S_{12} C_{1} C_{2}\left(t_{1}-t_{2}\right)^{2} \\
& -S_{13} C_{1} C_{3}\left[t_{1}^{2}-2 t_{1} t_{3}+t_{3}^{2}\right]=-S_{13} C_{1} C_{3}\left(t_{1}-t_{3}\right)^{2} \\
& -S_{23} C_{2} C_{3}\left[t_{2}^{2}-2 t_{2} t_{3}+t_{3}^{2}\right]=-S_{23} C_{2} C_{3}\left(t_{2}-t_{3}\right)^{2}
\end{aligned}
$$

Summing the three terms to the right of the equalities, we have an expression equivalent to that in brackets in the first form measure of the welfare cost. Since the bracket is multiplied by $\left(-\frac{1}{2}\right)$, we have for our third fundamental form of the measure for the welfare cost:

$$
\frac{1}{2} \sum_{j} \sum_{i<j} S_{i j}\left(t_{i}-t_{j}\right)^{2} C_{i} C_{j}
$$

The expression for the welfare cost of a set of taxes can be derived directly from utility functions as follows.

$$
U=U\left(X_{1}, X_{2}, \ldots, X_{n}\right)
$$

Taking a Taylor expansion up to quadratic terms, we have

$$
\begin{gathered}
\Delta U=\sum_{i} U_{i} \Delta X_{i}+\frac{1}{2} \sum_{i} \sum_{j} U_{i j} \Delta X_{i} \Delta X_{j}, \text { where } U_{i}=\frac{\partial U}{\partial X_{i}} \text { and } . \\
U_{i j}=\frac{\partial^{2} U}{\partial X_{i} \partial X_{j}} .
\end{gathered}
$$

Now $U_{i}$ is itself a function of the $X_{j}^{\prime}$ 's, so

$$
\begin{gathered}
U_{i}=U_{i}\left(X_{1}, X_{2}, \ldots, X_{n}\right), \text { and } \\
\Delta U_{i}=\sum_{j} U_{i j} \Delta X_{j} .
\end{gathered}
$$

Thus we can rewrite (2) as

$$
\Delta U=\sum_{i} U_{i} \Delta X_{i}+\frac{1}{2} \sum_{i} \Delta U_{i} \Delta X_{i}
$$

If consumers maximize utility subject to their money income and the prices facing them in any situation, we have, as a first-order condition of maximum, that

$$
U_{i}=\lambda P_{i}
$$

where $\lambda$ is a Lagrange multiplier representing the marginal utility of money. Obviously, from (6)

$$
\Delta U_{i}=\lambda \Delta P_{i}+P_{i} \Delta \lambda
$$

Substituting (6) and (7) into (5), we have

$$
\Delta U=\lambda \sum_{i} P_{i} \Delta X_{i}+\frac{1}{2} \lambda \sum_{i} \Delta P_{2} \Delta X_{i}+\frac{1}{2}(\Delta \lambda) \sum P_{i} \Delta X_{i}
$$


Interpreting the $P_{i}$ 's in (8) as representing the prices in an undistorted situation (i.e., as being proportional to unit costs), we have $\sum_{i} P_{i} \Delta X_{i}=$ $\sum_{i} k C_{i} \Delta X_{i}$, which must equal zero under our assumption of constant costs (linear transformation functions). Thus (8) reduces to

$$
\Delta U=\frac{1}{2} \lambda \sum_{i} \Delta P_{i} \Delta X_{i}
$$

To translate $\Delta U$ from utility terms into money terms, we must divide by the marginal utility of money. Thus money value of change in utility equals

$$
\frac{\Delta U}{\lambda}=\frac{1}{2} \sum_{i} \Delta P_{i} \Delta X_{i}
$$

which expressed as a cost is $-\frac{1}{2} \sum_{i} \Delta P_{i} \Delta X_{i}$. When the only disturbances between the two situations being compared are taxes, we have $\Delta P_{i}=T_{i}$. Thus from (10) we can derive $-\frac{1}{2} \sum_{i} T_{i} \Delta X_{i}$ as the measure of the welfare cost of a set of taxes $\left(T_{1}, \ldots, T_{n}\right)$. Moreover, since we require that changes in the $X_{i}$ all take place along a linear constraint, without first-order income effects, we can express $\Delta X_{i}=\sum_{j} S_{i j} \Delta P_{j}=\sum_{j} S_{i j} T_{j}$. Substituting this into $-\frac{1}{2} \sum_{i} T_{i} \Delta X_{i}$, we obtain

$$
-\frac{1}{2} \sum_{i} \sum_{j} S_{i j} T_{i} T_{j}
$$

as an alternative (equivalent) measure of welfare cost. This derivation is essentially the same as that given by $\mathrm{H}$. Hotelling. ${ }^{9}$ Hicks derives the expression $\frac{1}{2} \sum_{i} \sum_{j} S_{i j} T_{i} T_{j}$ (in his notation $\frac{1}{2} \sum_{r} \sum_{s} X_{r s} d P_{r} d P_{s}$ ) by a somewhat different route. ${ }^{10}$

\section{Measuring the Welfare Cost of Income Taxation}

In this section we apply the apparatus derived in the previous section to the problem of direct taxation with particular reference to the choice between labor and leisure. We shall disregard problems connected with the choice between consumption and saving, which will be dealt with separately below, and shall accordingly assume that all goods are direct consumption goods, and that all income is spent on such goods. The income tax will be represented as a flat-rate excise tax striking all goods (other than leisure) at the same percentage rate.

${ }^{\theta}$ "The General Welfare in Relation to Problems of Taxation and of Railway and Utility Rates," Econometrica, July 1938.

10 Value and Capital, p. 331. 
To begin, let us briefly review the traditional case for preferring direct to indirect taxation. Here leisure is not considered as a good, and the supply of work is asssumed to be unaffected by alterations in the pattern of taxation. The third fundamental form of the expression for welfare cost, i.e.,

$$
\frac{1}{2} \sum_{j} \sum_{i<j} S_{i j}\left(t_{i}-t_{j}\right)^{2} C_{i} C_{j}
$$

shows that an income tax has no welfare cost under the assumptions stated above. Since, under an income tax (with no concomitant excise taxes) $t_{i}=t_{j}$, for all. $i$ and $j$, every term in the summation is equal to zero.

On the other hand, no pattern of taxes on individual commodities can have a negative welfare cost, since by definition the welfare cost of a total set of taxes is measured against a neutral alternative. ${ }^{11}$ The best one could do, then, with unequal taxation of different goods, would be to have a zero welfare cost (such as would be the case if all goods but one were taxed equally, and the last good - taxed at a different ratehad a zero own-price elasticity of demand). But except in such curious and unrealistic cases, the welfare cost of a system of unequal excise taxes will be positive.

When leisure is introduced as a separate good, however, these statements no longer hold. Now an income tax must be interpreted as an equal-rate tax on all goods except leisure. Hence the income tax is no longer a truly general tax, and cannot be presumed to have a zero welfare cost. As Little has pointed out, in a world of three goods, $X_{1}, X_{2}$, and $X_{3}$, where $X_{3}$ is leisure, an equal percentage tax on $X_{1}$ and $X_{2}$ at the rate of $t_{1}=t_{2}$ leaves undistorted consumers' choices between $X_{1}$ and $X_{2}$, but distorts choices between $X_{1}$ and $X_{3}$ and between $X_{2}$ and $X_{3}$. On the other hand, taxing only $X_{1}$ distorts the choices between $X_{1}$ and $X_{2}$ and between $X_{1}$ and $X_{3}$, while leaving undistorted the choice between $X_{2}$ and $X_{3}$. Similarly, a tax on $X_{2}$ introduces distortions between $X_{2}$ and $X_{1}$, and between $X_{2}$ and $X_{3}$, but leaves choices between $X_{1}$ and $X_{3}$ undistorted. ${ }^{12}$ In each case a distortion is introduced into choices in two pairs of goods, and choice in the third pair is left undistorted. In this sense, therefore, an income tax is on a par with an excise tax. Any preference for income taxation, from a welfare point of view, must be

${ }^{11}$ Formally, the expression $\frac{1}{2} \sum_{i} \sum_{j} S_{i j} T_{i} T_{j}$ is negative or zero for any values of the $T$ 's. So $-\frac{1}{2} \underset{i}{\sum} \sum_{j} S_{i j} T_{i} T_{j}$ must be positive or zero. See Hicks, Value and Capital, p. 311 .

${ }_{12}$ I. M. D. Little, "Direct Versus Indirect Taxes," Economic Journal, September 1951, pp. 577-584. 
based on empirical considerations, not on a clear qualitative superiority of income taxation in all conceivable circumstances. We now turn, therefore, to the development of some propositions which will be of help in evaluating alternative patterns of taxation when the laborleisure choice is explicitly taken into account.

First, considering the case in which there are three goods, of which the third is leisure, we may inquire into the effect of an income tax (i.e., a tax on $X_{1}$ and $X_{2}$ at the percentage rate $t$ ). For convenience, let us introduce at this juncture a harmless convention-we choose our units of commodities in such a way that their unit cost, $C_{i}$, is unity for every commodity. Thus we may say that the unit of leisure, for a given individual, is that amount of time in which he would earn a dollar, if working. The units of $X_{1}$ and $X_{2}$ are amounts which sell for a dollar net of taxes. This enables us to leave out the $C^{\prime}$ 's in our expressions for welfare cost. The welfare cost of a tax at the rate $t$ on $X_{1}$ and $X_{2}$ is therefore

$$
\frac{1}{2}\left[S_{12}(t-t)^{2}+S_{13}(t-0)^{2}+S_{23}(t-0)^{2}\right]=\frac{1}{2}\left[S_{13} t^{2}+S_{23} t^{2}\right] .
$$

When the $C$ 's are equal to 1 , the restriction on the $S_{i j}$ 's is simply $\sum_{i} S_{i j}=\sum_{j} S_{i j}=0$. Thus $S_{13}+S_{23}=-S_{33}$, and the welfare cost of a proportional income tax at the rate $t$ can be expressed as $-\frac{1}{2} S_{33} t^{2}$. This expression is directly analogous to that for an excise tax on a single commodity. An excise tax on $X_{1}$ alone has a welfare cost of $-\frac{1}{2} S_{11} t_{1}^{2}$, and one on $X_{2}$ alone has a welfare cost of $-\frac{1}{2} S_{22} t_{2}^{2}$. This symmetry exists because a proportional income tax has the same effect on relative prices as a subsidy to leisure, and the expression $-\frac{1}{2} S_{33} t^{2}$ is the same for a given absolute value of $t$, regardless of whether $t$ is negative (subsidy) or positive $(\operatorname{tax})$.

In the above formula, taxes are expressed as percentages of the net prices (unit costs) of the corresponding commodities. Income-tax rates, however, are normally expressed as percentages of income before tax. It is worthwhile to establish at an early stage the relationships involved in the comparison of income taxes with "equivalent" excise taxes, so as to avoid confusion later on. A proportional income tax of $r$ per cent has as its counterpart an excise tax on the net prices of all goods other than leisure of $r /(1-r)$ per cent. That is, a 20 per cent income tax corresponds to an excise tax of 25 per cent on $X_{1}$ and $X_{2}$, for this creates a situation in which the gross prices of $X_{1}$ and $X_{2}$ exceed their net prices by 20 per cent of the gross price. Correspondingly, an income tax has the same effect on the allocation of resources as a subsidy at the rate of $r /(1-r)$ per cent on the net price of leisure. (Recall here that in this 
entire analysis we are holding the purchasing power of government receipts constant, so that if leisure were in fact to be subsidized directly there would have to exist a neutral-say, lump-sum — tax side by side with the subsidy on leisure so as to produce the required level of government receipts.) But a subsidy at the rate of $r /(1-r)$ per cent on the net price of leisure is equal to a subsidy of $r$ per cent on the gross price of leisure. Using $P_{n}$ and $P_{\theta}$ to represent net and gross price, respectively, we have

$$
P_{n}\left(1+\frac{r}{1-r}\right)=P_{g} ; \quad P_{n}\left(\frac{1}{1-r}\right)=P_{g} .
$$

This yields $P_{g}(1-r)=P_{n}$.

We can now render in diagrammatic form the expression $-\frac{1}{2} S_{33} t^{2}$. Let $L L$ be the supply curve of labor (defined so as to contain the substitution effect only). Let $w$ be the prevailing wage, gross of income tax. Then, where $r$ is the tax rate on gross income $r w(=A C)$ is the amount of tax per unit of labor, and $D A$ is the net-of-tax income per unit of

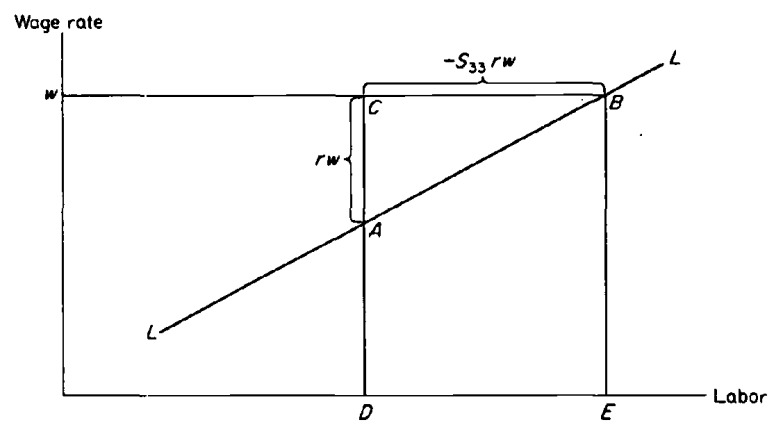

Figure 6

labor. Now $S_{33}$ is the derivative of the demand function for leisure with respect to the wage rate, so the derivative of the supply function of labor with respect tio the wage rate will be $-S_{33}$. Hence the reduction in the amount of labor performed as a consequence of an income tax at the rate $r$ will be $-S_{33} r w(=B C)$. The over-all reduction in gross money income to the worker will be $D E B C$. But the worker will have gained leisure valued at $D E B A$. This leaves as the net welfare cost of the tax the triangle $A B C$, or $-\frac{1}{2} S_{33}(r w)^{2}$. Recalling that $-S_{33}=$ $\frac{\partial L}{\partial w}$, this expression for welfare cost can be written

$$
\frac{1}{2} \frac{\partial L}{\partial v}\langle r w)^{2}=\frac{1}{2}\left(\frac{w}{L} \frac{\partial L}{\partial w}\right) r^{2} w L=\frac{1}{2} e r^{2} w L,
$$


where $e$ is the elasticity of supply of labor (expressing the substitution effect only), $w L$ represents the earnings of labor gross of income tax, and $r$ represents the rate of income tax expressed in the usual way as a percentage of gross income.

In order to apply this result to the United States case, we must first obtain an estimate of $e$, and then take account of the progressivity of the actual U.S. income tax. As far as $e$ is concerned, we have fairly reliable estimates on the secular pattern of response of hours worked to changes in real wages. Broadly speaking, a 1 per cent rise in real wages per hour has been associated with a reduction of .25 per cent in average hours worked. ${ }^{13}$ Unfortunately for our purposes, this historical

${ }^{13}$ Wages per hour of work in the manufacturing industry rose from $\$ .502$ in 1900 to $\$ 2.24$ in 1957, expressed in 1957 prices (Albert Rees, "Patterns of Wages, Prices, and Productivity," in Charles Myers, ed., Wages, Prices, Profits, and Productivity, New York, 1957, pp. 15-16). Average hours of work per week fell from 55 to 37.8 during the same period.

$\begin{array}{lcc} & \begin{array}{c}\text { Log Hours } \\ \text { Worked }\end{array} & \begin{array}{c}\text { Log Real Wages } \\ \text { Per Hour }\end{array} \\ 1900 & 1.74036 & 9.70070-10 \\ 1957 & 1.58771 & 0.35025 \\ \text { Difference } & .15265 & 0.64955\end{array}$

The elasticity of hours with respect to real hourly wages derived from these data is -.235 . The elasticities obtained from the regression of annual data on these two variables for the period 1900-57 (excluding the depression and war years) were -.26 for manufacturing, -.26 for railroads, -.19 for bituminous coal, and -.21 for anthracite coal. (See Ethel B. Jones, "Hours of Work in the United States, 1900-1957," unpublished Ph.D. dissertation, University of Chicago, 1961, p. 44.)

Obviously, using these figures to measure the elasticity of labor supply implicitly assumes that average hours tended to be those "desired" by workers, i.e., that workers were in some sense "on" their labor supply function. One need not labor the point that individual workers are constrained to some extent by the norms adopted in the particular places they work, so that a worker who desired to work only 30 hours a week would either have to find a job requiring this amount of work or be "off" his labor supply function. But it seems reasonable to suppose that the main force behind the historical downward trend in hours was the desire for additional leisure on the part of the typical worker. Unions would probably not have negotiated, and employers would probably not have conceded, reductions in normal hours of work if these reductions were not desired by the workers themselves. By the same token, there can be little doubt that wage rises were the principal force motivating the desire for greater leisure on the part of workers. Certainly, legislative changes do not account for a significant part of the reduction in hours. Laws imposing maximum hours affected only 4.1 per cent of workers in manufacturing by 1929 (ibid., p. 56). Jones concludes that only the Fair Labor Standards Act of 1938 is likely to have had a significant independent effect on hours worked in manufacturing, but finds that by the postwar period, actual hours in manufacturing were slightly above those which would be predicted by the pre-1929 relationships between average hours and real wage rates (ibid., p. 70). Actually, the major reductions in hours in the postwar period have come through increases in vacation and holiday time, which are unaffected by legislation and which seem to be a highly plausible form for workers to take increases in their "desired" leisure time. 
relationship reflects both the income effect and the substitution effect of wage increases. The problem is illustrated in Figure 7. In response to a rise in real wages, we observe an increase in the amount of leisure taken equal to $A^{\prime} C^{\prime}$. But this is composed of an income effect $A^{\prime} B^{\prime}$

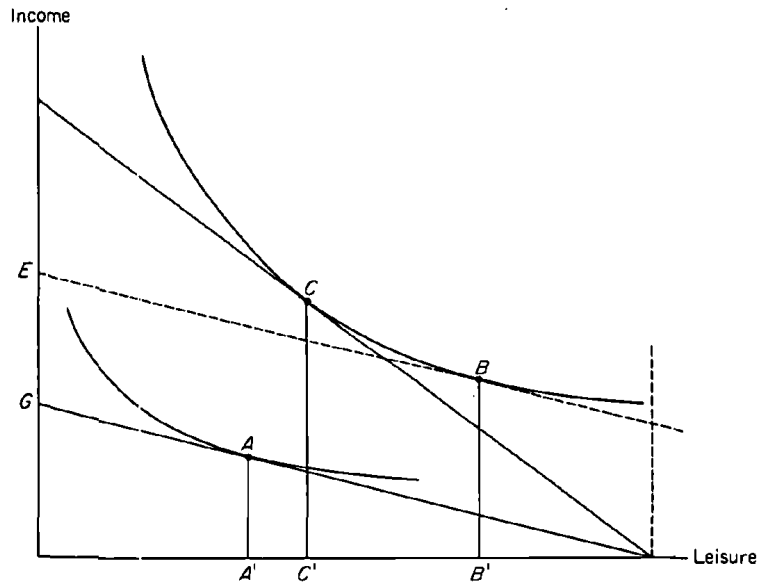

Figure 7

(such as would arise if the lower wage rate remained in effect and the worker inherited an annuity providing him with $G E$ of income per period) plus a substitution effect $B^{\prime} C^{\prime}$ (such as would take place if simultaneously the worker's annuity were canceled and the wage rate rose as depicted). Our problem is to guess at the possible magnitude of the income effect so as to be able to conclude something about the size of the substitution effect.

To put the problem in terms of the elasticity of supply of labor directly, let us define $\frac{\delta L}{\delta w}$ as the partial derivative of labor supply with respect to the wage rate, when the income effect is included, and $\frac{\partial L}{\partial w}$ as the corresponding partial derivative when the income effect is excluded. Let $\frac{\partial L}{\partial y}$ be the response of labor supply to a change in income (such as would come with the receipt of an annuity), holding the wage rate constant. Then we can write:

$$
\frac{\delta L}{\delta w}=\frac{\partial L}{\partial w}+\frac{\partial L}{\partial y} \frac{\partial y}{\partial w}
$$

Now with no other changes taking place, income will change by the number of hours worked times the change in the wage rate (i.e., $\Delta Y=$ 
$L \Delta w)$, so we can set $(\partial y / \partial w)=L$. Hence $\frac{w}{L} \frac{\delta L}{\delta w}=\frac{w}{L} \frac{\partial L}{\partial w}+w \frac{\partial L}{\partial y}$ or $e^{\prime}=e+w \frac{\partial L}{\partial y}$, where $e^{\prime}$ represents the elasticity of supply of labor including income and substitution effects and $e$ represents the elasticity of supply of labor including the substitution effect only. $w \frac{\partial L}{\partial y}$ is simply the negative of the fraction of an increase in nonlabor income which is taken out in the form of leisure. Thus if, for example, a worker on receiving an annuity of $\$ 1,000$ a year would reduce his labor earnings by $\$ 250$ a year, $w \frac{\partial L}{\partial y}$ would for him be -.25 . If he would reduce his labor earnings by $\$ 500$ a year, $w \frac{\partial L}{\partial y}$ would for him be -.50 .

Now, from historical observations, we take $e^{\prime}$ to be -.25 . Hence if $w \frac{\partial L}{\partial y}$ equaled $-.25, e$ must equal zero, and if $w \frac{\partial L}{\partial y}=-.50, e$ must equal +.25 . Since $e$ cannot be negative, and the available evidence indicates that $e^{\prime}$ is about -.25 , we cannot "guess" that $w \frac{\partial L}{\partial y}$ is less in absolute magnitude than .25. We can guess, however, that it is substantially less than .5 in absolute value. In order to have a specific number to play with, I shall assume that $w \frac{\partial L}{\partial y}=-.375$, indicating that a typical worker inheriting an annuity of $\$ 1000$ will tend to reduce his labor earnings by $\$ 375$. Readers need not take this guess too seriously, however, for the results that will be obtained using it can easily be adjusted for alternative assumptions.

When measuring the welfare cost of a proportional income tax, we can use the expression $\frac{1}{2} e r^{2} w L$ without further ado. But when the tax system is progressive, we must recognize that the choices of an individual at the margin are governed by his marginal tax rate, which we can call $m$. Letting $m_{i}$ be the marginal tax rate in the $i^{\text {th }}$ tax bracket, and $W_{i}=w_{i} L_{i}$ be the total wage income earned by people in the $i^{\text {th }}$ tax, bracket, we may express the total welfare cost of the personal income tax as $\frac{1}{2} \sum_{i} e_{i} m_{i}^{2} W_{i}$. This is what is done in Tables 2 and 3 . It is assumed that $e_{i}$ is equal to .125 for all tax brackets, on the basis of the value of -.375 for $w \frac{\partial L}{\partial y}$ selected above. Column 1 of Table 2 is merely for the information of the reader. The $\$ 331$ billion of reported income on returns with 
TABLE 2

WELFARE COST PER DOLLAR OF LABOR INCOME, BY ADJUSTED GROSS INCOME CLASS

\begin{tabular}{|c|c|c|c|c|c|}
\hline $\begin{array}{l}\text { Adjusted } \\
\text { Gross } \\
\text { Income } \\
\text { Class } \\
\text { (thousand } \\
\text { dollars) }\end{array}$ & $\begin{array}{c}\text { Total } \\
\text { Adjusted } \\
\text { Gross } \\
\text { Incoine } \\
\text { in Cliass } \\
\text { (thousiand } \\
\text { dollairs) } \\
\text { (1) }\end{array}$ & $\begin{array}{l}\text { Taxable } \\
\text { Income } \\
\text { Per } \\
\text { Return } \\
\text { with } \\
\text { Adjusted } \\
\text { Gross Income } \\
\text { in Class } \\
\text { (dollars) } \\
\text { (2) }\end{array}$ & $\begin{array}{c}\text { Marginal } \\
\text { Tax Rate } \\
\text { in Class } \\
\text { (per cent) } \\
\left(m_{1}\right) \\
(3)\end{array}$ & $\begin{array}{c}\text { Implied } \\
\text { Reduction in } \\
\text { Labor Supply } \\
\text { Within Class } \\
\text { (per cent) } \\
\left(e m_{1}\right) \\
(e=.125) \\
\text { (4) }\end{array}$ & $\begin{array}{c}\text { Welfare } \\
\text { Cost Per } \\
\text { Dollar } \\
\text { of Labor } \\
\text { Income } \\
\text { in Class } \\
\left(\frac{1}{2} \mathrm{em}_{1}^{2}\right) \\
\text { (5) }\end{array}$ \\
\hline 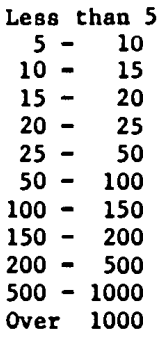 & $\begin{array}{r}84,2: 78 \\
144,9134 \\
48,5: 33 \\
15,151 \\
7,7: 38 \\
16,5914 \\
7,268 \\
2,01.5 \\
9: 16 \\
1,750 \\
663 \\
806\end{array}$ & $\begin{array}{r}887 \\
3,750 \\
7,865 \\
12,400 \\
16,906 \\
26,496 \\
53,659 \\
96,775 \\
136,488 \\
223,392 \\
528,092 \\
1,480,450\end{array}$ & $\begin{array}{l}.20 \\
.20 \\
.22 \\
.30 \\
.34 \\
.43 \\
.62 \\
.72 \\
.78 \\
.89 \\
.91 \\
.91\end{array}$ & $\begin{array}{r}2.50 \\
2.50 \\
2.75 \\
3.75 \\
4.25 \\
5.38 \\
7.75 \\
9.00 \\
9.75 \\
11.13 \\
11.38 \\
11.38\end{array}$ & $\begin{array}{l}.0025 \\
.0025 \\
.0030 \\
.0056 \\
.0072 \\
.0126 \\
.0240 \\
.0324 \\
.0380 \\
.0495 \\
.0518 \\
.0518\end{array}$ \\
\hline Total & 330,936 & & & & \\
\hline
\end{tabular}

Source: Statistics of Income: Individual Income Tax Returns for 1961, pp. $14-16$.

adjusted gross income compares with $\$ 427$ billion reported as total personal income in the national accounts for 1961. Column 2 of Table 2 presents the average adjusted gross income per return with adjusted gross income in each class. This figure was used to determine the marginal tax rate that would be assumed for each class in the calculations to follow. In obtaining the marginal tax rate from the tax table, the rates applying to joint returns were used. Thus a downward bias was introduced into the calculations of welfare cost. Column 4 of Table 2 presents the percentage reduction in labor effort within each class which is implied by the asisumptions of this analysis. It is meant to be a check on the plausibility of the results. As can be seen, the implied reductions in labor effort range from 2.5 per cent in the 20 per cent bracket to around 11.4 per cent in the 91 per cent bracket. This says, in effect, that if it were possible to extract out of each income class the same tax as was in fact obtained, but in such a way that tax incentives did not distort the choice between labor and leisure at the margin, we would get 11.4 per cent more work out of our top income brackets and 2.5 
TABLE 3

WELFARE COST ON WAGES AND SALARIES AND BUSINESS AND PROFESSIONAL INCOME, BY ADJUSTED GROSS INCOME CLASS

\begin{tabular}{|c|c|c|c|c|c|}
\hline $\begin{array}{l}\text { Adjusted } \\
\text { Gross } \\
\text { Income } \\
\text { Class } \\
\text { (thousand } \\
\text { dollars) }\end{array}$ & $\begin{array}{l}\text { Welfare } \\
\text { Cost Per } \\
\text { Dollar of } \\
\text { Labor } \\
\text { Income } \\
\text { in Class } \\
\text { (Table 2, } \\
\text { co1. 5) } \\
\text { (1) }\end{array}$ & $\begin{array}{l}\text { Wage and } \\
\text { Salary } \\
\text { Income in } \\
\text { Taxable } \\
\text { Returns } \\
\text { in Class } \\
\text { (thousand } \\
\text { dollars) } \\
(2)\end{array}$ & $\begin{array}{l}\text { Welfare Cost } \\
\text { on Wage and } \\
\text { Sa1ary Income } \\
\text { (cols. 1x2) } \\
\text { (thousand } \\
\text { dollars) } \\
(3)\end{array}$ & $\begin{array}{l}\text { Business and } \\
\text { Professional } \\
\text { Income } \\
\text { on Taxable } \\
\text { Returns } \\
\text { In Class } \\
\text { (thousand } \\
\text { dollars) } \\
\text { (4) }\end{array}$ & $\begin{array}{l}\text { Potential } \\
\text { Welfare } \\
\text { Cost on } \\
\text { Business and } \\
\text { Professional } \\
\text { Income } \\
\text { in Class } \\
\text { (cols. 1x4) } \\
\text { (thousand } \\
\text { do11ars) } \\
(5)\end{array}$ \\
\hline Less than 5 & .0025 & 58,418 & 146 & 4,371 & 11 \\
\hline $5-10$ & .0025 & 129,695 & 324 & 6,630 & 17 \\
\hline $10-15$ & .0030 & 40,448 & 121 & 3,434 & 10 \\
\hline $15-20$ & .0056 & 9,837 & 55 & 2,166 & 12 \\
\hline $20-25$ & .0072 & 4,145 & 30 & 1,468 & 11 \\
\hline $25-50$ & .0116 & 6,864 & 80 & 3,338 & 39 \\
\hline $50-100$ & .0240 & 2,452 & 59 & 991 & 24 \\
\hline $100-150$ & .0324 & 546 & 18 & 115 & 4 \\
\hline $150-200$ & .0380 & 185 & 7 & 33 & 1 \\
\hline $200-500$ & .0495 & 234 & 12 & 30 & 1 \\
\hline $500-1000$ & .0518 & 39 & 2 & 6 & -- \\
\hline \multirow[t]{2}{*}{ Over 1000} & .0518 & 19 & 1 & 5 & - \\
\hline & & 252,882 & 855 & 22,587 & 130 \\
\hline
\end{tabular}

Source: Statistics of Income: Individual Income Tax Returns for 1961, pp. 14-16.

per cent more work out of people presently in the lowest range of taxable income. These figures do not imply that top-bracket people work less than low-bracket people, but only that they work 11 or so per cent less than they would in the absence of the income-tax incentive for leisure.

Much work has still to be done to enrich the theory underlying this analysis and to check its implications in detail. However, I would suggest the following principal sources of the reduction in labor effort, particularly in the higher brackets:

1. Longer vacations (winters in Florida, etc.).

2. A higher incidence of early retirement.

3. Less labor force participation of women.

4. Less supplemental labor income from sources other than main employment.

And I find it quite plausible that these factors might account for a 5 per cent reduction in labor effort in the $\$ 25,000-\$ 50,000$ bracket, and for an 11 per cent reduction in the highest brackets, as against what it would be in the absence of tax incentives at the margin, but in the 
presence of the existing total weight of tax. Needless to say, I do not expect everybody to agree with this judgment, but shall proceed on this basis in the absence of any alternative that seems clearly better to me.

Column 5 of Table 2 (reproduced as column 1 of Table 3) gives the estimated welfare cost per dollar of labor income in each class. In column 2 of Table 3 we have the amount of wage and salary income (by far the major category of labor income) declared on taxable returns in each class, and in column 3 the estimated welfare cost associated with the tax incentive to wage and salary earners. In column 4 we have the amount of business and professional income declared on taxable returns in each class. Obviously not all of this income comes from labor effort, but the estimates of welfare cost in column 5 are based on the extreme assumption that business and professional income is all labor income. Since the welfare costs estimated in column 5 are not large compared with those in column 3, I elected not to attempt an adjustment to exclude that fraction of business and professional income which might be attributable to property.

The results emerging from Table 3 suggest that the welfare costs associated with the distortion of the labor-leisure choice by the personal income tax may be of the order of $\$ 1$ billion per year. My own reaction to this is twofold. First of all, $\$ 1$ billion is not a very large amount in comparison to the $\$ 42$ billion per year raised by the personal income tax in 1961. If this were a necessary cost to obtain the kind of progression that the personal income tax contributes to our tax system, I would judge it to be a worthwhile cost. But the roughly $\$ 1$ billion per year cost estimated in Table 3 is clearly not a necessary cost to obtain the existing degree of progression in the personal income tax structure. Actually, the average tax rate (income-tax adjusted-gross-income) does not reach 45 per cent even for the highest brackets, and for most brackets is only about half the marginal tax rate. ${ }^{14}$ This means that there are real possibilities for obtaining about as much revenue from each class as at present, but with lower marginal rates. This can be done by broadening the tax base (reducing exemptions and deductions, eliminating or modifying a host of special provisions such as percentage depletion and capital gains, etc.). Most tax experts have advocated such a reform

14 The average tax rates in 1961 by bracket are: 7.2 per cent for $0-\$ 5,000 ; 11.0$ per cent for $\$ 5,000-10,000 ; 14.3$ per cent for $\$ 10,000-15,000 ; 17.0$ per cent for $\$ 15,000-$ 20,$000 ; 19.5$ per cent for $\$ 20,000-25,000 ; 24.5$ per cent for $\$ 25,000-50,000 ; 34.2$ per cent for $\$ 50,000-100,000 ; 40.1$ per cent for $\$ 100,000-150,000 ; 42.4$ per cent for $\$ 150,000-200,000 ; 43.7$ per cent for $\$ 200,000-500,000 ; 44.8$ per cent for $\$ 500,000$ $1,000,000$; and 42.4 per cent for over $\$ 1,000,000$. 
of our tax system, and the present analysis simply adds support to the proposal. If, for example, the marginal rate in each class of adjusted gross income could be reduced to seven-tenths of its present value, the welfare cost estimated above would be cut about in half. And it is likely that this could be done without loss of either revenue or effective progressivity.

\section{Comparison of the Welfare Costs of Direct and Indirect Taxation}

In this section we attempt to assess the relative merits of direct and indirect taxation taking explicit account of the issues raised by the labor-leisure choice. Throughout this section we shall set aside the problem of progressivity and consider the income tax as a proportional tax, and as equivalent to a set of excise taxes striking all goods other than leisure at the same percentage rate. The first question we ask is: Granted that the income tax has a certain welfare cost, under what circumstances does it have a smaller welfare cost than a set of excise taxes at unequal rates which yields the same revenue? Second, we turn to the theoretical question of how to measure the difference in welfare costs between an excise tax and an income tax yielding the same revenue. Third, we turn to the more interesting question of how we would measure the change in welfare costs resulting from eliminating an existing excise tax and substituting for it an increment to an already existing income tax.

To answer our first question, let us again postulate a three-commodity world, in which the third good is leisure. We are allowed to tax only goods 1 and 2, and we are required to raise a given amount of revenue. The expression for welfare cost, when commodity units are chosen so that unit costs equal 1 , is

$$
-\frac{1}{2}\left[S_{11} t_{1}^{2}+S_{22} t_{2}^{2}+S_{33} t_{3}^{2}+2 S_{12} t_{1} t_{2}+2 S_{13} t_{1} t_{3}+2 S_{23} t_{2} t_{3}\right]_{3}=
$$

Because our problem restricts $t_{3}$ to be zero, this reduces to

$$
-\frac{1}{2}\left[S_{11} t_{1}^{2}+S_{22} t_{2}^{2}+2 S_{12} t_{1} t_{2}\right] .
$$

We seek to minimize this expression by our choice of $t_{1}$ and $t_{2}$, subject to the constraint that $t_{1} X_{1}+t_{2} X_{2}=K$, i.e., that a given amount of total revenue, $K$, is obtained. Minimizing

$$
W=-\frac{1}{2}\left[S_{11} t_{1}^{2}+S_{22} t_{2}^{2}+2 S_{12} t_{1} t_{2}\right]+\lambda\left[t_{1} X_{1}+t_{2} X_{2}-K\right],
$$


TAXATION, RESOURCE ALLOCATION, WELFARE

we obtain

$$
\begin{aligned}
& \frac{\partial W}{\partial t_{1}}=-S_{11} t_{1}-S_{12} t_{2}+\lambda X_{1}=0 \\
& \frac{\partial W}{\partial t_{2}}=-S_{22} t_{2}-S_{12} t_{1}+\lambda X_{2}=0 .
\end{aligned}
$$

The solution for $t_{1}$ and $t_{2}$ for minimum welfare cost is

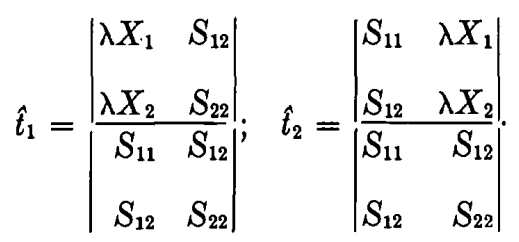

Obviously, $\hat{t}_{1}$ will equal $\hat{t}_{2}$ when the numerators of the above expressions are equal, i.e., when

$$
X_{1} S_{22}-X_{2} S_{12}=X_{2} S_{11}-X_{1} S_{12}
$$

Using the fact that, when unit costs $=1, S_{11}=-S_{12}-S_{13} ; S_{22}=$ $-S_{12}-S_{23}$, this equality can be rewritten

$$
-X_{12} S_{12}-X_{2} S_{12}-X_{1} S_{23}=-X_{2} S_{12}-X_{1} S_{12}-X_{2} S_{13} \text {. }
$$

Hence the equality requires that $X_{1} S_{23}$ be equal to $X_{2} S_{13}$, or that $S_{13} / X_{1}=S_{23} / X_{2}$. But $S_{13}=\frac{\partial X_{1}}{\partial P_{3}}$; and with $P_{3}=1, \eta_{13}$, the cross elasticity of demand for commodity 1 with respect to the price of leisure can be written $\frac{1}{X_{1}} \frac{\partial X_{1}}{\partial P_{3}}=\frac{S_{13}}{X_{1}}$. Likewise, $S_{23} / X_{2}=\eta_{23}$. Hence the condition for equal excise taxation of both goods being the best pattern of excise taxation by which to raise a given sum of money is that both goods have the same cross elasticity of demand with respect to the price of leisure.

To see under what circumstances a minimum welfare cost is obtained with a lower (or a higher) tax on $X_{1}$ than $X_{2}$, we can express the ratio $\hat{t}_{1} / \hat{t}_{2}$ as:

$$
\frac{\hat{t}_{1}}{\hat{t}_{2}}=\frac{X_{1} S_{12}+X_{2} S_{12}+X_{1} S_{23}}{X_{1} S_{12}+X_{2} S_{12}+X_{2} S_{13}}
$$

Obviously, when $X_{: L} S_{23}$ is smaller than $X_{2} S_{13}, \hat{t}_{1}$ is less than $\hat{t}_{2}$. This can happen when $S_{23}$ is negative, i.e., when $X_{2}$ is complementary to leisure, or when, $S_{23}$ and $S_{\mathrm{t} 3}$ both being positive, $X_{1} S_{23}<X_{2} S_{13}$. This last inequality is equivalent to $\eta_{23}<\eta_{13}$. Thus the tax on $X_{1}$ "should" be 
lower than the tax on $X_{2}$ whenever $X_{2}$ is less substitutable for leisure than is $X_{1}{ }^{15}$

This result should not be taken to suggest, however, that it is likely that minimum-welfare-cost patterns of excise taxation are likely to have very different rates. Dividing both numerator and denominator in the above expression by $X_{1} X_{2}$, and recalling that $S_{12}=S_{21}$, we obtain:

$$
\frac{\hat{t}_{1}}{\hat{t}_{2}}=\frac{\eta_{21}+\eta_{12}+\eta_{23}}{\eta_{21}+\eta_{12}+\eta_{13}}
$$

If, as is likely, the cross elasticity of both goods with respect to the price of leisure is low in comparison to the cross elasticities of the goods with respect to each other's prices, the ratio of $\hat{t}_{1}$ to $\hat{t}_{2}$ will not be "very" different from unity.

We now turn to the second question mentioned at the beginning of this section-measuring the difference in welfare cost between an excise tax and an income tax of equal yield. The welfare cost of an excise tax at the rate $t_{1}$ is simply

$$
C_{1}=-\frac{1}{2} S_{11} t_{1}^{2}
$$

A proportional income tax at the rate $t^{x}$ will have equal yield when $t^{x}\left(X_{1}+X_{2}\right)=t_{1} X_{1}$, i.e., where $t^{x}=t_{1} X_{1} /\left(X_{1}+X_{2}\right)$. The welfare cost of this income tax will be

Hence we may write

$$
C_{2}=-\frac{1}{2} S_{33}\left(t^{x}\right)^{2}
$$

$$
\begin{gathered}
C_{1}-C_{2}=-\frac{1}{2}\left[S_{11} t_{1}^{2}-S_{33}\left(t^{x}\right)^{2}\right], \text { or } \\
C_{1}-C_{2}=-\frac{1}{2} S_{11} t_{1}^{2}\left[1-\frac{S_{33}}{S_{11}}\left(\frac{t^{x}}{t_{1}}\right)^{2}\right] .
\end{gathered}
$$

This equation expresses the difference in welfare cost between an excise tax and an equal-yield income tax as the welfare cost of the excise tax taken by itself times one minus a "correction factor" $\left[\frac{S_{33}}{S_{11}}\left(\frac{t^{x}}{t_{1}}\right)^{2}\right]$. Now $\frac{t^{x}}{t_{1}}$ is simply $X_{1} /\left(X_{1}+X_{2}\right)$, or the fraction of money income accounted for by the taxed commodity. Calling this measure $a_{1}$, we may express the correction factor as $\left[S_{33} /\left(X_{1}+X_{2}\right)\right]\left[X_{1} / S_{11}\right] a_{1}$. Now $X_{1} / S_{11}$ is simply $1 / \eta_{11}$. Now, as indicated in the preceding section $-S_{33}$ is equal to the derivative of the supply of labor with respect to the wage

\footnotetext{
${ }^{15}$ For an early analysis arriving at essentially the same conclusion, though by a somewhat more complicated argument, see W. J. Corlett and D. C. Hague, "Complementarity and the Excess Burden of Taxation," Review of Economic Studies, 1953-54, pp. 21-30.
} 
$\left(P_{3}\right)$. Where all income is produced by labor, and all prices are unity, $\left(X_{1}+X_{2}\right)$ represents the quantity of labor supplied. Therefore $-S_{33} /\left(X_{1}+X_{2}\right)$ is equal to $e$, the elasticity of supply of labor. Hence $\left[\frac{S_{33}}{S_{11}} \cdot\left(\frac{t^{x}}{t_{1}}\right)^{2}\right]$ can be expressed as $-a_{1} e / \eta_{11}$. Since $\eta_{11}$ is necessarily negative, the correction factor is positive. What is more important, however, is the fact that the correction factor is likely to be very small, as long as the excise tax is not so general as to be nearly an income tax itself. In the preceding section we judged a plausible value for $e$ to be .125. Suppose we consider $t_{1}$ to be an excise tax which strikes 20 per cent of all goods and services other than leisure, i.e., $.2=X_{1} /\left(X_{1}+X_{2}\right)=a_{1}$. The correction factor will then be equal to $-(.2)(.125) / \eta_{11}$, or $-.025 / \eta_{11}$. Thus if the own-price elasticity of demand for the taxed good were as small in absolute value as .25 , the correction factor would only be .1 ; and if the elasticity were in the range between -.5 and -1.0 , the correction factor could, for all practical purposes, be neglected. Only when the elasticity of demand for the excise-taxed commodity is very small indeed would the correction factor become of sizable magnitude. And this elasticity would have to be virtually zero (in our example, less than .025) in order for the correction factor to exceed unity, and thus for the excise tax to have lower welfare cost than an equal-yield income tax.

The result just obtained is heartening to those who felt all along that direct taxation is better than indirect taxation. But the case just covered is one in which the excise tax and the income tax are strictly alternatives, and as such it is far removed from reality. We shall now modify the preceding example to allow for an income tax already in existence, and shall inquire about the size of the difference between the increments to welfare cost incurred by either adding a given amount to total revenue by way of an excise tax on $X_{1}$, or adding the same amount to total revenue by increasing the rate of income tax.

Let $t_{0}$ be the existing rate of income tax, and, as before $t_{1}$ and $t^{x}$ be the alternative increments to tax rates. The situations we are comparing then are

$\begin{array}{ccc} & \text { Tax Rate on } X_{1} & \text { Tax Rate on } X_{2} \\ \text { Situation 1 } & t_{0}+t_{1} & t_{0} \\ \text { Situation 2 } & t_{0}+t^{x} & t_{0}+t^{x},\end{array}$

where, as before, $t^{x}=a_{1} t_{1}$.

The expressions for the welfare cost are in this case most conveniently expressed in terms of the third fundamental form $\frac{1}{2} \sum_{j} \sum_{i<j} S_{i j}\left(t_{i}-t_{j}\right)^{2}$. 


$$
\begin{aligned}
& C_{1}=\frac{1}{2}\left[S_{12} t_{1}^{2}+S_{13}\left(t_{0}+t_{1}\right)^{2}+S_{23} t_{0}^{2}\right] \\
& C_{2}=\frac{1}{2}\left[S_{13}\left(t_{0}+t^{x}\right)^{2}+S_{23}\left(t_{0}+t^{x}\right)^{2}\right] .
\end{aligned}
$$

Expanding, we have

$$
\begin{aligned}
& C_{1}=\frac{1}{2}\left[S_{12} t_{1}^{2}+S_{13} t_{0}^{2}+2 S_{13} t_{0} t_{1}+S_{13} t_{1}^{2}+S_{23} t_{0}^{2}\right] \\
& C_{2}=\frac{1}{2}\left[S_{13} t_{0}^{2}+2 S_{13} t_{0} t^{x}+S_{13}\left(t^{x}\right)^{2}+S_{23} t_{0}^{2}+2 S_{23} t_{0} t^{x}+S_{23}\left(t^{x}\right)^{2}\right] .
\end{aligned}
$$

Subtracting, we obtain

$$
\begin{aligned}
C_{1}-C_{2}=\frac{1}{2}\left[S_{12} t_{1}^{2}+2 S_{13} t_{0} t_{1}+S_{13} t_{1}^{2}-2 S_{13} t_{0} t^{x}-S_{13}\left(t^{x}\right)^{2}\right. & \left.-2 S_{23} t_{0} t^{x}-S_{23}\left(t^{x}\right)^{2}\right] .
\end{aligned}
$$

Since $S_{12}+S_{13}=-S_{11}$, and $-S_{13}-S_{23}=S_{33}$, this reduces to

$$
C_{1}-C_{2}=\frac{1}{2}\left[-S_{11} t_{1}^{2}+S_{33}\left(t^{x}\right)^{2}+2 S_{13} t_{0} t_{1}-2 S_{13} t_{0} t^{x}-2 S_{23} t_{0} t^{x}\right]
$$

Substituting $a_{1} t_{1}$ for $t^{x}$ in the last two terms, we have

$$
\begin{aligned}
& C_{1}-C_{2}=\frac{1}{2}\left[-S_{11} t_{1}^{2}+S_{33}\left(t^{x}\right)^{2}+2\left(1-a_{1}\right) S_{13} t_{0} t_{1}-2 a_{1} S_{23} t_{0} t_{1}\right] . \\
& C_{1}-C_{2}=-\frac{1}{2} S_{11} t_{1}^{2}\left[1-\frac{S_{33}}{S_{11}}\left(\frac{t^{x}}{t_{1}}\right)^{2}-2 \frac{\left(1-a_{1}\right) S_{13} t_{0}-a_{1} S_{23} t_{0}}{S_{11} t_{1}}\right] .
\end{aligned}
$$

Once again we are expressing the difference in the welfare cost of an excise tax and (in this case) an increment to the income tax rate as being equal to the welfare cost of the excise tax by itself times one minus a correction factor. For simplicity, let us say one minus two correction factors. The first of these, $\frac{S_{33}}{S_{11}}\left(\frac{t^{x}}{t_{1}}\right)^{2}$, has already been shown to be equal to $-a_{1} e / \eta_{11}$, and likely to be small.

We therefore turn to an evaluation of the second correction factor, 2. $\frac{\left(1-a_{1}\right) S_{13}-a_{1} S_{23}}{S_{11}}\left(\frac{t_{0}}{t_{1}}\right)$. First let us convert this relationship into elasticity form, using $S_{13}=X_{1 \eta_{13}} ; S_{23}=X_{2 \eta_{23}}$ and $S_{11}=X_{1 \eta_{11}}$. This yields

$$
\text { 2. } \frac{\left(1-a_{1}\right) X_{1} \eta_{13}-a_{1} X_{2} \eta_{23}}{X_{1} \eta_{11}}\left(\frac{t_{0}}{t_{1}}\right) \text {. }
$$

Now let us define $a_{2}=X_{2} /\left(X_{1}+X_{2}\right)=\left(1-a_{1}\right)$. Dividing numerator and denominator by $\left(X_{1}+X_{2}\right)$, we obtain

$$
\text { 2. } \frac{a_{2}\left(\eta_{13}-\eta_{23}\right)}{\eta_{11}}\left(\frac{t_{0}}{t_{1}}\right)
$$

The correction factor will be positive if the taxed commodity $\left(X_{1}\right)$ is complementary with leisure $\left(\eta_{13}<0\right)$, or if, both goods being substitutes for leisure, the taxed commodity is the poorer substitute $\left(0<\eta_{13}<\eta_{23}\right)$. This simply reflects the fact that the minimum-welfare-cost pattern of taxing $X_{1}$ and $X_{2}$ calls for higher taxation of the poorer substitute for 
leisure. But it is to be emphasized that the sign of the second correction factor could be ejther positive or negative, and that neither sign is more likely than the other. The sign depends only on whether the commodity chosen for excise taxation happens to be a better-than-average or a worse-than-average substitute for leisure.

It is to be presumed that in most cases the second adjustment factor will be of small magnitude, at least where the tax rate $t_{1}$ is not very small in relation to the existing income tax rate, $t_{0}$, and where the ownprice elasticity of demand for $X_{1}$ is not itself very small.

Another way of expressing the second correction factor is

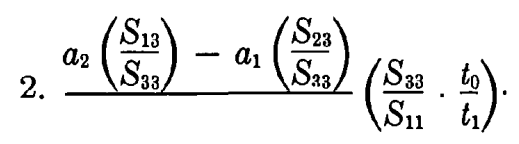

Since $S_{13}+S_{23}=-S_{33},\left(\frac{S_{13}}{S_{33}}\right)$ and $\left(\frac{S_{23}}{S_{33}}\right)$ must add up to -1 . In the normal case where $X_{1}$ and $X_{2}$ are both substitutes for leisure, $\frac{S_{13}}{S_{33}}$ and $\frac{S_{23}}{S_{33}}$ will both be negative fractions. Calling them $f_{1}$ and $f_{2}$ respectively, the second correction factor can be rewritten as

$$
\text { 2. }\left(a_{2} f_{1}-a_{1} f_{2}\right) \frac{S_{33} t_{0}}{S_{11} t_{1}}
$$

$\left(S_{33} t_{0} / S_{11} t_{1}\right)$ is simply the ratio of the welfare cost per dollar of tax receipts of the existing income tax to the welfare cost per dollar of tax receipts of the excise tax under consideration, divided by $a_{1}$, the share of the taxed commodity in total income. The welfare cost of the income tax is $-\frac{1}{2} S_{33} t_{0}^{2}=\frac{1}{2}\left(X_{1}+X_{2}\right) e t_{0}^{2}$. The revenue from the income tax is $\left(X_{1}+X_{2}\right) t_{0}$, as the welfare cost per dollar of revenue is $\frac{1}{2} e t_{0}$. The welfare cost of the excise tax on $X_{1}$, in turn, is $-\frac{1}{2} S_{11} t_{1}^{2}=-\frac{1}{2} X_{1} \eta_{11} t_{1}^{2}$. It yields $X_{1} t_{1}$ in revenue, so the welfare cost per dollar of tax is $-\frac{1}{2} \eta_{11} t_{1}$. Hence if we call $h_{0}$ and $h_{1}$ the welfare costs per dollar of revenue of the existing income tax and the excise tax under consideration, respectively, we can write $\left(S_{33} t_{0} / S_{11} t_{1}\right)==h_{0} / a_{1} h_{1}$. Hence the correction factor is equal to

$$
2\left(\left[a_{2} f_{1} / a_{1}\right]-f_{2}\right)\left(h_{0} / h_{1}\right) \text {. }
$$

Where the welfare cost per dollar of revenue is significantly higher for the excise tax than for the existing income tax, the correction factor is likely to be small. When $e=.125$, the welfare cost of an income tax, per dollar of revenue, will range between $\$ .0125$ and $\$ .0250$ for tax rates between .2 and .4 , for example. When $\eta_{11}=-1$, on the other hand, the welfare cost of an excise tax of 20 per cent will be $\$ .10$ per dollar of tax 
revenue. Thus where an excise tax is likely to look bad (i.e., to have a high welfare cost per dollar of tax revenue) when taken by itself, it is also likely to look bad in comparison with the alternative of adding to an existing income tax. When, on the other hand, an excise tax is contemplated which does not look bad by itself, we cannot be confident that an increase in income tax designed to produce an equal increment of revenue would be a preferable alternative.

The conclusion that I draw from this exercise is, therefore, that by and large the traditional preference for direct over indirect taxation is justified, and that the simple textbook measure of welfare cost (the triangle under the demand curve) yields a good first approximation in most cases.

\section{Taxation and the Incentive to Save}

We now turn to a consideration of how taxation influences welfare through its effect on saving. Here we have another area where income taxation is nonneutral. The private incentives to save are governed by the after-tax yield on the sums involved, but the social rate of return is given by the before-tax yield. Clearly, in order to make the tax system neutral with respect to savings decisions, one would require a consumption tax of the type that Kaldor has proposed, rather than an income tax of the conventional type.

Having recognized the nonneutrality of income taxation with respect to savings, we now turn to the measurement of the welfare costs that it entails. The solution to this problem is not as clear-cut as that of labor-leisure choice. The difficulty arises because the introduction of savings into the picture injects a dynamic element into what would otherwise be a comparative static model. This can be handled neatly if the time path of savings is independent of the changes in tax policy under consideration, but in such a case income taxation would have no welfare cost arising from interference with the savings decision, and our problem would disappear. As long as we take our problem seriously, we must face up to a possible effect of taxation on the volume of savings and investment, and thus the problem of incorporating a dynamic element in what would otherwise be a static model must be faced.

I shall discuss here two alternative ways of dealing with the above problem, the first of which inquires into the purpose for which the saving in question is undertaken, and the second of which does not. The first approach starts by taking a particular time-horizon for a given act of saving-say, ten years. If $\$ 1$ is saved now, and if its full social yield 
(at the rate $\rho$ ) is reinvested, it will produce, ten years from now, a sum equal to $\$ 1(1+\rho)^{10}$. If, however, the yield of this saving is annually taxed at the rate $t$, its private value ten years from now will be $\$ 1(1+r)^{10}$, if $r=\rho(1-t)$ is the private rate of return on savings. The marginal rate of substitution in consumption between present goods and goods ten years in the future will therefore be $1:(1+r)^{10}$, while the social marginal rate of transformation will be $1:(1+\rho)^{10}$. The percentage excess of $(1+\rho)^{10}$ over $(1+r)^{10}$ plays the same role as would a tax of this percentage on savings made for the purpose of accumulation for ten years and for consumption at the end of the period. Similarly, the percentage excess of $(1+\rho)^{n}$ over $(1+r)^{n}$ plays the same role as a corresponding tax on savings made for the purpose of accumulation for $n$ years and then for consumption. Since in the real world savings are not made for purposes as clearly specified as these, one may regard the effects of income taxation as being equivalent to a tax on savings at a rate equal to a weighted average of the expressions $\left[(1+\rho)^{n} /(1+r)^{n}-1\right]$, the weights reflecting the probabilities attaching to the savings being used in particular future time periods.

The approach just outlined has the advantage of emphasizing the way in which the effects of tax incentives upon saving depend on what might be called the savings strategy of the affected individuals. The marginal rate of substitution between this year's goods and next year's goods is not likely to be much affected even by very heavy income taxation; while the marginal rate of substitution between this year's goods and goods a quarter century from now will be substantially affected, even by comparatively moderate income taxation. For example, taxing away 50 per cent of the income from capital, in a case where $\rho$, the social marginal productivity of capital, is 6 per cent, changes the marginal rate of substitution between present and future goods from 1.06 to 1.03 for one-year savings decisions, from 1.34 to 1.16 for five-year savings decisions, from 1.79 to 1.34 for ten-year savings decisions, and from 3.21 to 1.81 for twenty-year savings decisions. But by the same token, this approach runs into the difficulty of having to specify the savers' strategies with respect to reinvestment and consumption out of capital.

The second approach is simpler, neater, and more conventional. It simply regards each dollar saved as purchasing a perpetual income stream in the amount of $\$ \rho$ per year for the society as a whole, and of $\$ \rho(1-t)$, or $\$ r$ per year for the individual saver. The present value of this income stream to the saver, evaluated at the rate $r$, is $\$ 1$. But the present value to society is $\$ \rho / r$. The social value of a marginal dollar of 
saving thus exceeds the private value by the percentage $t /(1-t)$. If the elimination of this distortion would produce a change in savings equal to $\Delta S$ dollars, then we can assign as the welfare cost of the distortion of the savings decision the amount $\frac{1}{2}(\Delta S)[t /(1-t)]$.

I must confess that I have labored for some time under a prejudice against this second approach, mainly because the idea of persons considering saving only in terms of perpetuities did not seem particularly realistic. However, further reflection has led me to conclude that my original objection was not a serious one. The essential difference between the two approaches lies in their treatment of decisions taken at different times. The first approach tries to deal simultaneously with the saving that takes place now, with the reinvestment of the earnings of that saving for some period in the future, and with the disinvestment of the accumulated value at the end of the period. The second approach deals only with the savings decisions taken at a given period in time. This year's savings are considered when the analysis focuses on this year's actions; next year's savings are taken into account when the analysis focuses on next year's actions, etc. In particular, the second approach does not ask what will be done next year with the earnings on this year's savings; it simply treats those earnings as part of the total income accruing next year, in terms of which the individual will reach a decision as to how much to save. Nor does the second approach treat the realization of the proceeds of a given investment as an act of dissaving; it looks instead at the total movement in the capital stock of an individual in a given year. If this capital stock has increased, the individual has saved, net, regardless of how many previous investments may have been liquidated during the year. It seems to me, therefore, that the second approach, in addition to being simpler and more convenient to handle in the analysis of welfare costs, also looks at the savings decision in a scientifically more sophisticated way.

Before leaving the subject of the effects of taxation on the rate of saving, we should inquire whether the distortions introduced by income taxation can lead to an increase in the rate of saving. It is well known that where changes in the rate of return on savings include an income effect, a reduction in the rate of return can produce an increase in the volume of savings. Does this possibility emerge in the case under discussion? The answer, I believe, is clearly negative. Income effects are kept out of the picture, in this analysis, by the requirement that the government be able, year by year, to buy the same bundles of goods under any alternative patterns of taxation being compared. If we were 
to consider the effects of reducing the rate of income taxation, without imposing any alternative tax to make up for the lost revenue, then an income effect would be present, and a decrease in saving could conceivably result. However, if we require that the government make up for the lost revenue; say, by increasing the rate of consumption taxation, then no first-order income effect will be present, and the change in the rate of savings must be in the same direction as the change in the net-oftax rate of return.

Consumers in their role as savers see their future income reduced because of the tax that they have to pay on the return to capital under an income tax. But if the shift were made to a pure consumption tax, they would see their future income reduced because of the higher tax they would have to pay on their future consumption expenditures. ${ }^{16}$ Consumers will in fact get more future income under a consumption-tax setup than under an equal-yield income tax, but they will do so only because they save more as a consequence of the higher return they perceive on their capital. If they save exactly the same amounts under the two setups, the extra future income they get from their capital will be just counterbalanced by the extra future taxes they have to pay on their consumption when they face a consumption rather than an income tax.

In spite of a clear presumption that the taxation of income from property will reduce the rate of savings as against what it would be under neutral taxation of equal yield, it is very hard to build an empirical case for the proposition that the taxation of property income has significantly affected the savings rate. But one must recognize that it would not require a phenomenal responsiveness of savings to the net rate of return in order to generate a fairly significant welfare cost as a consequence of the distortion of the savings-consumption decision. If net savings, for example, were only 1 per cent of the national income less than they would be under straight consumption taxation, the welfare cost of taxes striking the income from capital at a $33 \frac{1}{3}$ per cent rate would be roughly $\frac{1}{2}(.01)(.50)$ times the national income. This is .25 per cent of national income, or a sum of over $\$ 1$ billion per year at present levels.

What rankles me much more than the possible effect of our tax system on the total volume of savings, however, is the way in which our taxes influence the uses to which our savings are put. The heavy weight of taxes on income from capital can be justified on equity grounds in a

${ }^{16}$ See Martin J. Bailey, National Income and the Price Level, New York, 1962, pp. $180-182$. 
number of ways, but the grossly unequal tax treatment of different types of income from capital cannot be seriously defended by appeals to equity considerations. Most risky corporate investments, which have little chance to be financed by debt capital, have the worst of it, while oil wells are powerfully subsidized to produce petroleum at real cost far above what it would take to obtain the oil from abroad. Income is freely transmuted into capital gains in a variety of activities (lumber, coal mining, rental housing, cattle feeding), inducing an excessive flow of resources into these fields. Perhaps the most blatant case is that of owner-occupied housing which is allowed to generate no taxable income, just tax deductions. The stimuli given by the tax treatment of owneroccupied housing are virtually nil for the needy, and increase directly with the opulence of the taxpayer. It is easy to establish that these tax incentives give rise to a substantial misallocation of investible funds, with a consequent cost to consumers throughout the economy. Elsewhere $^{17}$ I have tried to establish the order of magnitude of the losses involved due to tax-induced misallocations of our capital stock. Roughly speaking, $\$ 1$ billion per year (say, between $\$ .5$ and $\$ 1.5$ billion) seems to be the right order of magnitude for the distortions caused by the corporation income tax. Percentage depletion and related provisions appear to cost the economy between $\$ .5$ and $\$ 1.0$ billion per year. David Laidler, in a study currently nearing completion, estimates the cost to the economy of the inefficiencies introduced by the special treatment of owner-occupied housing to be in the order of $\$ .5$ to $\$ 1.0$ billion per year. Taking all these costs together, and recognizing that there are a number of important tax incentives to the allocation of investment which are not accounted for above, I think that a clear case can be made for rationalizing our manner of taxing income from capital so as not to discriminate so severely among different allocations of capital resources.

\section{Taxation and Growth}

It is likely that the feature which best distinguishes the economic thinking (both professional and popular) of the postwar period from earlier decades is the emphasis placed upon economic growth-as a phenomenon to be explained, as a criterion of economic performance, and as an ob-

${ }^{17}$ Arnold C. Harberger, "The Taxation of Mineral Industries," in Federal Tax Policy for Economic Growth and Stability, Washington, Joint Committee on the Economic Report, 1955, pp. 439-49, and "The Corporation Income Tax: An Empirical Appraisal," in Tax Revision Compendium, U.S. House of Representatives, Ways and Means Committee, Washington, 1959. 
jective of policy. In today's environment it is quite natural, therefore, to inquire into the likely effects of alternative policies upon the rate of growth. In the terms of reference of this conference, and of my paper, this boils down to the question of how significantly the rate of growth could be influenced by plausible changes in the mix of direct and indirect taxation. I think that the answer is not very much.

The modern approach to the empirical analysis of economic growth (used, with only slight variations, by Abramovitz, Denison, Fabricant, Kendrick, Schultz, and Solow, among others) is to split up observed growth into a pari; attributed to the increase in labor inputs, a part attributed to the increase in capital inputs, and a residual not explained by these factors. The part assigned to labor is this year's growth in man-hours times laist year's average wage; this procedure uses last year's average wage as a measure of what the marginal product of the added labor would be in the absence of technical progress and of changes in the quality of labor. The part assigned to capital is this year's net investment times last year's average before-tax rate of return to capital; once again last year's observed rate of return is used as a measure of what added capital would contribute to national income in the absence of technical advance and other forces not taken directly into account. The breakdown of the change in output from one period (year) to the next can be summarized as:

$$
\Delta Y_{t}=w_{t-1} \Delta L_{t}+\rho_{t-1} I_{t-1}+T_{t}, \text { where }
$$

$\Delta Y_{t}=$ change of national income (or net national product) between period $t-1$ and period $t$ (expressed in dollars of $t-1$ ).

$\Delta L_{t}=$ change in labor input (man-hours) between period $t-1$ and period $t$.

$w_{t-1}=$ average wage per man-hour in period $t-1$.

$\rho_{t-1}=$ average (gross-of-tax) rate of productivity of capital (net of depreciation) in period $t-1$.

$I_{t-1}=$ net investment in period $t-1$.

$T_{t}=$ the amount of growth of national income between $t-1$ and $t$ which is unexplained by changes in labor and capital inputs (expressed in dollars of $t-1$ ).

The formula above can be divided by $Y_{t-1}$ so as to express the dependency of the rate of growth of income on various factors:

$$
y_{t}=S_{t-1} l_{t}+\rho_{t-1} i_{t-1}+r_{t}, \text { where }
$$

$y_{t}=\frac{\Delta Y_{t}}{Y_{t-1}}=$ rate of growth of income in year $t$. 
$S_{t-1}=\frac{w_{t-1} L_{t-1}}{Y_{t-1}}=$ share of labor in the national income in year $t-1$.

$l_{t}=\Delta L_{t} / L_{t-1}=$ rate of growth of labor input in year $t$.

$i_{t-1}=I_{t-1} / Y_{t-1}=$ rate of net investment in year $t-1$.

$r_{t}=T_{t} / Y_{t-1}=$ percentage increase in income in year $t$ which is unexplained by changes in labor and capital inputs.

The earlier sections of this paper were devoted to the possible effects of direct and indirect taxation on the supply of labor and on the volume of savings. There is a clear presumption that greater resort to indirect taxation would increase the supply of labor, though the magnitude of the increase would not be very great. The rough guesses of column 4 of Table 2 suggest that approximately a 3 per cent increase in the supply of labor could be obtained by eliminating the inducements to leisure implied by our present marginal personal income-tax rates. But to get to this result in practice would require constructing a tax system in which there were no inducements favoring leisure over labor at the margin. The more likely alternatives to our present income-tax structure, such as greater reliance on broad-based indirect taxes, would not go this far; they would only reduce, not eliminate, the incentives toward leisure at the margin. Thus we should probably think of plausible shifts toward more indirect taxation as leading to a substantially less than 3 per cent increase in the supply of labor, under given conditions. This change in the supply of labor would increase the measured national output (assuming full employment), but would not necessarily contribute to the normal rate of growth of output. Any contribution of decreased leisure to the rate of growth of output would have to come from its influence either on the rate of growth of the labor supply or on the share of labor in total income. I see no reason to expect any significant change in either of these magnitudes as a consequence of shifting the mix of direct and indirect taxation; $;^{18}$ hence I would put down as negligible the possible contribution of such shifts to the over-all rate of growth.

As distinct from their influence on growth via the labor-leisure choice, there are more significant possibilities for shifts between direct and in-

${ }^{18}$ It is clearly possible to influence the long-run rate of growth of the labor force by tax measures explicitly aimed at this objective. I have no doubt, for example, that the birth rate could be influenced by changes in income-tax exemption policy, or by indirect taxes on goods specific to child-raising. And any change in the birth rate would in the long run have its effect on the normal rate of growth of the labor force. But I do not believe that any of us consider specific measures aimed at influencing population growth to be within the terms of reference of this conference, and accordingly will not pursue the matter further. 
direct taxation to alter the rate of growth via their effects on saving. These can be conveniently represented if we make the assumption that, through time, the marginal rate of productivity of capital remains constant. If this rate is 10 per cent, and net investment (= net savings) increases from 8 to 9 per cent of the national income, the rate of growth of output should on that account change by .10 per cent per annum (.10) $\times(.01)$. Increasing the rate of net saving from 8 to 10 per cent of the national income will, in these circumstances, add .20 per cent per annum to the rate of growth.

Influencing the rate of growth by .10 or .20 of a percentage point may seem small, but it is not negligible in the sense that I have labeled the impact on growth via the labor-leisure choice as negligible. In discussing the effects on growth via savings, I shall first consider what kinds of effects on savings we might plausibly expect to come even from drastic changes in tax policy, and then proceed to deal with the possibility that the formulation of the growth process presented above might understate the contribution of added savings.

Although there has been some debate as to the degree to which the marginal propensity to save increases with income, I believe that there can be little doubt that it does increase. Existing studies of saving by income class do not include accruing capital gains either as part of income or as part of saving, yet in principle they should do both. Thus studies measuring income and savings on the conventional basis can yield what purportis to be a constant marginal propensity to save, or only a mildly increasing one, and yet a correctly measured marginal propensity to save might be a significantly increasing function of income.

As far as I know, no study exists which incorporates accruing capital gains in both income and savings; hence I cannot bring evidence to bear on this subject. But making extreme assumptions often allows one to get an idea of the possibilities. Suppose, for example, that the marginal propensity to save were 50 per cent for all incomes above $\$ 20,000$ per year, and 10 per cent for all incomes below $\$ 20,000$. Suppose, moreover, that in a drastic tax revolution all incomes above $\$ 20,000$ were entirely relieved of income tax, and that the entire income-tax burden now borne by them were placed (via direct or indirect taxation) on income brackets below $\$ 20,000$. What would be the effect on savings? In 1961 , adjusted gross incomes above $\$ 20,000$ paid less than $\$ 11$ billion of income tax. If these groups were relieved of this burden altogether, they would, on our absurd assumptions, save $\$ 5.5$ billion more. And if lower brackets were required to bear $\$ 11$ billion more of tax, they would, 
on our assumptions, save $\$ 1.1$ billion less. There would be a net increase in savings of $\$ 4.4$ billion, or just about 1 per cent of the 1961 national income.

Now I cannot imagine that plausible redistributions in the tax burden would be nearly so drastic as that assumed above. Nor do I find it plausible that differences in marginal propensities to consume are as sharp as those assumed above. Hence I conclude that the redistributive effects associated with plausible tax changes are not likely. to increase saving by more than, say, .50 per cent of the national income.

The evidence we have on the substitution effects of taxation upon saving is even less secure than that on the redistributive effects. Here, appeal is often made to the observed secular constancy of the ratio of savings to income, and the conclusion is drawn, in the face of fairly substantial changes in the perceived rate of return, that the substitution effects in question are small. I adhere in general to this position, though it must be recognized that income effects were also present in the situations producing the observed data. Until we can isolate the magnitude of the income effects that were at work, we should not conclude that the substitution effects which operated to roughly offset the income effects were minor in importance. Having said this, however, let me add that I would be surprised if plausible tax changes (e.g., a shift from income to expenditures as the base of our major progressive tax) would increase national savings by more than $1,1.5$, or 2 per cent of the national income.

If these rough judgments can be accepted, we must face the fact that tax changes are unlikely to increase the rate of growth of national income by more than .10 or .20 of a percentage point-unless the model set out at the beginning of this section has a serious flaw.

The flaw which would be the most likely to change the growth-rate implications of the preceding analysis would be an underestimation of the social marginal productivity of investment (= savings). If investment carries with it positive external effects on output, the average perceived gross-of-tax rate of return would understate the contribution of investment to the growth of national income, and our imputation would understate the part of observed growth due to capital accumulation.

Solow, in a highly original paper, has attempted to cope with this possibility by requiring that technical advances be "embodied" in capital equipment before they produce increases in output. ${ }^{19}$ His method was to

${ }^{19}$ R. M. Solow, "Technical Progress, Capital Formation, and Economic Growth," American Economic Review, May 1962, pp. 76-86. 
assume that the capital equipment produced in year $t$ was $100 \lambda$ per cent "better" (i.e., mole productive) than that produced in year $t-1$. Working with this assumption, Solow reconstituted existing data making gross investment in year $t$ "equivalent" to that of the base year by taking $I_{t}^{\prime}=I_{t}(1+\lambda)^{\imath}$, where $I_{t}$ is the conventional measure of gross investment (in constant dollars) and $I_{t}^{\prime}$ is the measure incorporating the improved productivity of investment in year $t$ over the same constantdollar volume of investment in year 0. Proceeding on this basis, Solow builds up a time series on capital stock from the adjusted gross investment data, together with retirement estimates based on Terborgh's figures. He estimates separate capital stocks for plant and equipment, introducing the possibility of separate $\lambda$ 's for these two categories of capital. He ends up with one series for capital stock associated with $\lambda$ 's of .02 for both plant and equipment; another associated with $\lambda$ 's of .03 for both plant and equipment, andothree more for other combinations $(.02, .03),(.02, .04),(.03, .04)$ of $\lambda$ 's for plant and equipment. He then introduces these alternative measures of capital stock along with variables measuring labor input and unemployment, into a production function of the Cobb-Douglas type (modified to incorporate the unemployment variables). His results improve as he moves from capital stock estimates based on lower values for $\lambda$ to those based on higher values.

Solow's device appears to yield some mileage, as far as the effect of investment on growth is concerned. Whereas on our assumption of a 10 per cent rate of productivity on capital, it takes a 10 percentage point increase in the fraction of income invested to produce a 1 percentage point change in the growth rate, Solow achieves the same effect by an increase of 2.5 percentage points in the fraction of income invested.

However, Solow's results depend critically on his assumption that there are no independent forces producing economic growth. Eitan Berglas, in a recently completed study, has followed Solow's procedure for calculating capital stock, but has allowed for the production function to shift with time as a result of independent forces as well. ${ }^{20}$ Berglas finds that the best explanation of observed changes in output, under this hypothesis, emerges when the $\lambda$ 's for plant and equipment are both set at zero-i.e., when the conventional measure of capital stock is used. More important, as long as a trend shift of production functions is allowed for, the effect of investment on output is no greater when $\lambda$ is high than when it is zero. That is, adjusting the capital stock to incor-

\footnotetext{
${ }^{20}$ Eitan Berglas, "Stimulating Investment: Costs and Effects," unpublished Ph.D. dissertation, University of Chicago, 1963, Chapter 5.
} 
porate assumed rates of technical improvement does not add to the estimated effect of investment on economic growth-regardless of what positive values of $\lambda$ are chosen.

It seems to me that Berglas' reformulation of Solow's procedure must be preferred to the original. In the first place, we know that there are forces which have had a trend influence on total factor productivity in the economy that are not directly associated with the volume of investment-improvements in the quality of the labor force and advances in the art of management are two cases in point. This knowledge should dictate a procedure which would allow for a trend shift of production functions as one of the explanatory factors of changes in output. If, when trend shifts were allowed for, they proved to have an insignificant explanatory power, we could conclude that they have been unimportant. But this is not the result that emerges. In fact, the trend variables introduced by Berglas are highly significant statistically (with $t$ ratios lying between 8 and 15 for various assumptions regarding $\lambda$ ). Moreover, they lead to plausible coefficients for the capital input in the CobbDouglas production function (around .25 for $\lambda=0$, as opposed to 1.31 for $\lambda=0$ when trend is not taken into account, and .52 for $\lambda=.03$ when trend is not taken into account). I want to emphasize that, though Berglas' study suggests that $\lambda=0$ is the best hypothesis for explaining observed changes in output in the presence of a trend shift in production functions, this is not the real lesson to be learned from his experiments. For $\lambda=.03$, when trend is allowed for, Berglas explains 99.31 per cent of variations in output per man-hour over the period 1929-60; while for $\lambda=0$ he explains 99.46 per cent of the same variations. There is thus not much basis for choice among different plausible values of $\lambda$. The important result emerging from Berglas' study is that higher values of $\lambda$ do not mean that investment has a greater influence on economic growth than is obtained when $\lambda$ is assumed to be zero. In short, Berglas' work has put us back into the situation where an extra percentage point of national income devoted to investment will affect the rate of growth by around .10 of a percentage point.

Berglas' conclusions are fortified by additional experiments. In the first, an effort was made to see whether the rate of growth depended significantly on the "newness" of the capital stock. To test this hypothesis, the cumulated gross investment of a period, expressed as a percentage of initial capital stock, is used to explain changes in total factor productivity over the same period in different industries. This was done for thirteen two-digit industries, for the periods 1948-57, 
1948-53, and 1953-57. In none of these cases did a significant correlation appear, and in two of the three (1948-57 and 1953-57) the correlation was mildly negative. Similar results emerged when cumulated investment for 1948-53, expressed as a fraction of capital stock, was used to explain changes in total factor productivity between 1953 and 1957. This last effort was an attempt to allow for a possible lag between investment and subsequent improvement in total factor productivity.

The limited power of added investment to improve the growth rate should not really be surprising. It does not deny that, each year, technical advances make particular investments highly productive. Nor does it imply that the allocations presented at the beginning of this section are correct. I suspect, in fact, that there is a substantial degree of "embodiment" of technical advances in particular types of capital goods with high prospective marginal productivity. Each year, I think, technical improvements create prospects of very high rates of return in certain investments, say, 30,25 , or 20 per cent. The contribution of these investments to economic growth is greater than $\rho$, the average observed rate of return to capital. If we ranked investments according to prospective rates of return, forming a function $I=f(\rho)$ where $f^{\prime}(\rho)<0$, we could state the contribution of investment to economic growth as $I \rho_{0} t \int_{\rho_{0}}^{\infty} f(\rho) d \rho$, which would exceed the amount assigned to investment by the expression $I \rho_{t-1}$ where $\rho_{t-1}=\rho_{0}$. The difference would be that inframarginal investments would then be assigned a greater contribution to economic progress. But, when we are talking about increasing the growth rate by adding to investment, we are not concerned with inframarginal investments, but about those beyond what would otherwise be the cut-off rate of return. There is nothing inconsistent between the following three statements:

1. Each year some investments are undertaken which promise to yield, at prevailing prices, very high rates of return.

2. Each year significant amounts of investment are undertaken which promise yields in the neighborhood of the observed past rate of return.

3. Additional investments above and beyond those actually undertaken would likely produce rates of return which are at best equal to the observed past average rate of return.

According to the point of view just expressed, "embodiment" of technical changes takes place principally in inframarginal investments. This sort of phenomenon could easily produce the results observed by Berglas, with the marginal effect of investment being approximated by the ob- 
served past average rate of return, but with a substantial time trend in the ratio of output to total input. It is also consistent with the observation that, across industries or time periods, there is relatively little relationship between the rate of increase in capital stock and the movements in total factor productivity.

This is not the place for a very detailed discussion of these points, so I will leave the matter here. I hope tleat I have been able to provide some support for my view that we cannot expect great changes in the growth rate from plausible changes in the mix of direct and indirect taxation.

I feel impelled, however, to point out that in our recent preoccupation with the rate of growth, we, as a profession, may have lost sight of some old and fundamental truths. We should distinguish between the rate of growth of income, the level of income, and the level of welfare as possible goals of economic policy. Concentration on the rate of growth as an objective can lead one to minimize the value of having, say, $x$ per cent more income each year as a result of a policy change-simply because income would not grow any faster except during a transitional period. On the other hand, concentration on the level of real income (as conventionally measured) can lead one to neglect the costs of bringing about changes in that level. If, by tax changes, we increase labor and reduce leisure, or if we increase saving and reduce consumption, we should, I think, not just look at the pluses and neglect the minuses. When we try to take both pluses and minuses into account, we come to grips with the measurement of the effects of policy changes on welfare, which was the subject of the earlier sections of this paper.

\section{COMMENT}

\section{E. Cary Brown, Massachusetts Institute of Technology and University of Chicago}

After reading through the major papers prepared for this conference, I was impressed by the near unanimity of emphasis on two matters. The first was that the labels direct and indirect taxation are neither very enlightening nor very helpful in analyzing questions of fiscal policy. May I fashionably record my full agreement with this view. The second was the extended analysis given to value-added taxation. My thought was that we might more accurately have called this the value-added tax 
conference. And I am hopeful that, by the end of it, we will have added some value to the economy.

\section{WELFARE AND RESOURCE ALLOCATION}

Let me turn then to the rigorous analysis Harberger has made of the welfare and resource-allocation implications of income and excise taxes for economic growth. At the heart of the problem of growth is, of course, the concern with economic welfare, and Harberger has properly drawn our attention to it repeatedly and pressed for quantitative measurement of it. His discussion shows clearly that there are no easy answers, that any feasible tax is inefficient in that it involves dead-weight losses, and that there may be a mild advantage in direct over indirect (really income over excise) taxes.

I certainly cannot disagree with these views. But it may be well to re-emphasize the strictures he placed on his analysis: (1) that resources are fully employed and (I would add, as I am sure he would) efficiently employed in production; (2) constant government expenditures; (3) constant unit costs; and (4) no redistribution of income. The first assumption is clearly necessary to keep the welfare costs of unemployment out of the picture. The second one, while necessary for measuring the welfare costs of alternative taxes, may require relaxation in discussing problems of growth, as we shall see presently. The third is a justifiable simplification; it can be relaxed without damaging the analysis. The fourth-that income is not redistributed-may well be the most awkward. It makes the problem the rather unrealistic one of raising a given amount of revenue from a particular taxpayer by alternative fiscal devices. If we were all endowed with equal incomes and tastes, this approach would obviously be meaningful. But any conceivable shift in the tax structure involves some redistribution of income, and when this arises no measure of welfare loss or gain can be made without making interpersonal welfare comparisons either explicitly or implicitly.

Besides these strictures, we should always bear in mind two additional sets of problems. Marginal rates of transformation and substitution can differ for a variety of reasons other than the kind of tax imposed. It has often been pointed out in the literature that an excise tax on commodities produced under purely competitive conditions may actually increase welfare when one product is monopolized, compared with a completely neutral tax system. Or, put in another way, we must start from the best position. Last, but not least, we are ultimately interested in equating marginal social costs and marginal social benefits. We cannot avoid 
making comparisons of social costs and social benefits; we cannot adopt the easy assumption that private costs and benefits stand for their social equivalents. It may be that some distortions in private resource use created by taxation meet more closely with society's wishes than complete neutrality would. Here, again, it is difficult to say anything quantitatively, but just such a question lies at the heart of the issue of whether more economic growth, for example, will increase the community's welfare, especially if bought at any cost.

Some of these difficulties are seen when we attempt to measure the welfare losses of taxes that distort savings-consuming decisions. They arise not only in a comparison of consumption versus income taxes, but also in determining the mix between monetary and fiscal policy. To rule out the tax question, suppose that the government can impose lump-sum taxes in whatever amount it wishes. Suppose also that there are diminishing returns to capital, that investment has a negative substitution response to interest rates, and that consumption, to the extent that it responds, does so in the same way. Suppose also that the size of the budget deficit or surplus is a matter of indifference, but that real government expenditures are fixed. We can then visualize an infinite number of combinations of lump-sum taxes and interest rates that will keep us on the production-possibility frontier. At any one interest rate and tax level, consumers will make savings decisions that will change their lifetime configuration of consumption compared with some other combination. Because there would be no difference between marginal rates of transformation and substitution of present and future goods, would each of these positions yield the same welfare? And if one could be reached by some combination of taxes which included an income tax, should we then say there was a welfare loss in that position compared with another?

The problem of optimal rates of saving raises difficult and perplexing questions, as Harberger has amply emphasized. His approach to measuring the welfare loss is certainly ingenious and interesting. While abiding by his strictures, however, I would measure the loss in a slightly different way. I would sum up the present values of the welfare costs arising from changes in consumption over time using some weighting procedure similar to his, but I would discount them to the present. In comparing welfare losses of excise taxes, for example, we are comparing present consumption of one type with present consumption of another. In the consumption-saving case, we are adding up present and future welfare losses. To add them up, it seems to me, requires that they be 
made homogeneous by a discounting procedure. Otherwise we would get infinite welfare losses for those who save permanently. The proper discount rate to use is certainly debatable: should it be society's marginal product from saving or the private marginal product? I lean toward using the after-tax interest rate, rather than the before-tax rate, because this is the rate seen by the consumer. This comes very close to Harberger's formulation, but puts it in present-value terms.

To conclude then on welfare matters, I would not want to leave the impression that I think that they are unimportant. On the contrary, taxes do create dead-weight losses which we should seek out and correct wherever we can. The work that Harberger has undertaken is a significant contribution toward an understanding of these problems. But it can only be the first step toward appraising the welfare implications of taxation, because of the problems of income redistribution and externalities.

\section{GROWTH}

I turn now to the question of economic growth. About this Harberger has much less to say; but I would agree with his position, as I understand it. The (disembodied) Solow and Denison have shown that the job of increasing the growth rate by increasing investment is difficult indeed; and while the (embodied) Solow has given us more hope, it is not an easy task. It requires large changes in rates of saving and investing, in labor force participation, or in productivity changes to step up the rate very much. This is not to say that small changes are insignificant and unimportant, but we cannot expect major changes without major revisions in economic policy.

Broadly speaking, revisions in tax policy can be classified into three categories: structural changes that leave the distribution of income alone; structural changes that also redistribute income; and structural changes that increase the level of taxation, holding government expenditures constant-that is, that alter the full-employment surplus or deficit.

The analysis that economists have brought to bear on the first kind of change generally suggests that no major results would flow from a shift toward indirect taxes, if the distribution of income were kept the same. The work-leisure choice certainly would be largely unaffected under these circumstances. The saving-consumption decision would be affected by the tax postponement under a consumption tax. While the implicit interest-rate change would not appear to provide much inducement for important shifts in consumer behavior, the fact that consump- 
tion taxes act as a capital levy on existing wealth held for future consumption (a point Kaldor has properly emphasized) may give them more leverage than would appear at first glance. But still it is difficult to think of substantial increases in saving coming about in this way.

But the direct-indirect, or consumption-income, tax revision almost surely is motivated by a desire for redistribution of the tax load. Progressive income taxation inevitably requires higher marginal rates than proportional or regressive income or consumption taxation. Attention is then focused on reducing these high marginal rates because, other things being equal, they have a more distorting effect than lower-rate taxes. Or, even if they did not, one may believe that distortions in work-leisure and consumer-saving decisions of the high-income group are particularly damaging to growth because of the crucial quality of their effort or of their saving. All we can honestly say here, I suppose, is that we do not know. Such evidence as we have does not suggest important gains will be observed in saving or effort from redistribution of income. And I should emphasize that this has little to do with the form of taxes-whether direct or indirect-but the income groups from which they come.

At this point a cryptic word should be said about the heavy taxation of corporations. There are fiscal devices short of a complete overhaul of this tax which appear to provide a substantial blunting of its adverse effects on investment-through loss offsets, accelerated depreciation, or investment credits. The loss-offset argument is a powerful one to my mind, given the substantial possibilities to absorb losses open to the going concern, and given the way that corporate losses can transmigrate. Indeed, instead of impeding the market in corporate shells, perhaps we should be advocating steps to perfect it.

Finally, we come to changes in the level of taxation, and again its significance seems to have little to do with the nature of the tax. Waiving political problems, there is virtually no limit to the degree to which consumption outlays can be reduced and resources freed for investment. Substantial changes in growth rates, requiring, say, a 20 or 25 per cent increase in plant and equipment outlays, would call for heroic measures along this line coupled with a substantial stimulation of investment, either by easy money to domestic long-term borrowers or by special incentive devices. Whether or not it could succeed is something about which we have a right to be dubious. But it would have vastly more chance of success than merely shifting existing taxes, and would depend primarily on the size, rather than the kind, of additional taxes imposed. 
Indeed, if the size of the debt imposes political restraints on fiscal policy, it may be far wises: to impose taxes with the least effect on consumption in order to maximize the budget surplus with a given level of consumption.

It is easy to lock around the world and find examples of rapid economic growth coupled with high indirect taxes. It is also easy to find counter examples. Indeed, in looking at various states in this country, I suspect it may be nearer the truth that economic growth determines tax structures rather than the other way around. But, rather than end on such a skeptical note, let me re-emphasize my agreement with Harberger that the large distortions in investment decisions brought about by capital gains and by the treatment of the mineral industries and owner-occupied dwellings could well be eliminated to our economic gain.

\section{William Fellnef, Yale University}

I feel considerable respect for Harberger's contribution and am sure the conference feels the same way; I therefore believe that my comments should concentrate on those parts of Harberger's argument which in my view should be qualified. One or two of the questions which I intended to raise have already been discussed by Brown and so I will not raise them again.

On a much lower level of abstraction than that of Harberger's paper, some economists (including myself) have suggested that, given the conditions of the 196io's, the weight of direct taxes relative to that of indirect taxes may be too great in the American tax structure. Arguments of the following sort have been used:

1. The relative weight of direct taxes is appreciably greater in our tax system than in that of any other major country.

2. All non-lump-sum taxes push the taxpayer around, that is to say, they violate the Psireto conditions.

3. For various reasons, sales taxes on nonnecessities may be said to push the taxpayer in directions more consistent with avowed policy objectives than does the individual income tax or the corporate profits tax.

4. While ideally income taxes and corporate profits taxes could be shaped in such a way as to be milder violators of the Pareto conditions than are excises, it is not at all obvious that in reality they can be so shaped.

5. Last but not least, while blueprints of the graduated income tax make this tax appear to be more equitable than other taxes, the observ- 
able deviations from the blueprints are very significant indeed, so that in the final analysis one would hesitate to make a stronger statement than that in some ways the graduated income tax, as we know it, is more equitable than indirect taxes are but in various other ways the income tax is particularly inequitable.

On the basis of considerations no more refined than these, some of us have questioned whether it is wise for the United States to maintain a direct-to-indirect ratio of roughly 1.6 to 1 when all other major countries have a ratio of less than 1 to 1 . Even if smaller countries are included in the comparison, our ratio is probably the highest in the world with the exception of Sweden. I mean here the ratio of central and local government revenues from direct taxes to revenues from indirect taxes, with social security contributions excluded from both categories. The place of the United States in such rankings does not seem to depend to any great extent on the treatment of social security. Nor do I believe that our place in the ranking could have been affected appreciably by changes that have occurred since 1957, the year for which the above figures are given.

On this lower level of analytical refinement, it is difficult to gauge the effect that the fiscal program of the present administration may have on our direct-to-indirect ratio without making very specific assumptions about the prospective increase in GNP and about the GNPelasticity of different kinds of tax revenue. But I do believe that some lowering of the American ratio may be expected for the 1960's, particularly in view of the rising trends in state and local indirect taxation.

Turning now to Harberger's study, one may ask to what extent the great analytical ingenuity expressed in his paper is helpful in guiding the reader's judgment about the desirable direct-indirect mix. About this I feel somewhat skeptical, although not entirely negative. The reason for my skepticism is that his conclusions, which in his words are "heartening to those who felt all along that direct taxation is better than indirect," are in the end more dependent on very risky numerical guesses than appears to be the case at first sight.

$T_{0}$ argue this point I must engage in a few numerical exercises which, however, need to be combined with analytical considerations. Let me hasten to add that I consider it a real merit of Harberger's paper that it can serve as a basis for such exercises-no doubt also for more elaborate ones than those here.

I will begin by saying that the data which Harberger uses in Section III to discuss the reduction of weekly hours as a result of wage 
increases during the period 1900-57 may be strongly influenced by the fact that a reduction of hours and a rise in average hourly earnings frequently come in one institutional package. Strong unions must be aware of the likelihood that if a demand for a shorter normal workweek proves successful, and the actual workweek is shortened, this makes it easier to bargain for higher hourly earnings, partly because the labor market is made tighter and partly because it is obviously not the intention to let the workers pay out of their weekly earnings for any large share of the price of their additional leisure. If the wage rate earned by individual workers were increased and all other contractual and institutional factors were held constant (but the workers in question were allowed to vary the number of hours performed), they might have significantly less incentive to reduce their work time than they do in the actual circumstances in which the two gains come in one package. Furthermore, other things equal, the shortening of the workweek increases the income of some workers who with a longer workweek might find it more difficult to obtain employment-this is the work-spreading effect of the shorter workweek-and, to the extent that unions are guided by this particular objective, the data do not lend themselves at all to estimating the elasticities with which Harberger is concerned. If for these reasons someone suggested that Harberger should have estimated $e^{\prime}$ to be merely one-half of -0.25 (rather than -0.25 ), I would have no strong convictions about who was right.

Also, if someone suggested that Harberger should have estimated his $W \frac{\partial L}{\partial y}$ term at -0.50 rather than at his wholly conjectural figure of -0.375 , I would have no strong convictions about which guess was more realistic. Perhaps if the average worker received a large gift in the form of a perpetual annuity, he would use over his lifetime one-half of this windfall to secure for himself and members of his family additional leisure (and only helf of the gift would accrue as a net addition to money income), while if the wage rate rises substantially he would utilize a much higher proportion of the additional earnings potential for the acquisition of additional earnings. Who knows? Reason does set limits to guesswork in such matters, but in this case the limits are very wide indeed. If $e^{\prime}$ were -0.125 and $W \frac{\partial L}{\partial Y}$ were -0.50 , the estimate of $e$ would have to be changed from Harberger's -0.125 to -0.375 .

Finally, perhaps the problem of excises should be considered as a problem of comparing a rather general taxation of nonnecessities with a 
taxation of income; in other words, the intuitively interesting problem might be conceived as one of excises imposed on, say, between 30 and 40 per cent of the output. If now the demand-elasticity of the taxed goods were between -0.5 and -0.6 , this would mean that the method used in Section IV of Harberger's paper would yield for the income tax a welfare cost of roughly 25 per cent or more (instead of a negligible fraction) of the welfare cost of the excises. I think such guesses are no more but also no less relevant than Harberger's. I would not even say that he has estimated a lower limit and that I am supplying an estimate of an upper limit. I would merely say that guesses on the basis of which the welfare cost of income taxes is a negligible fraction of the welfare cost of excises are no better and no worse than guesses on the basis of which the welfare cost of income taxes amounts to, say, 25 per cent or more of that of excises.

Pragmatically there is a big difference between concluding that the welfare cost of the income tax is a negligible fraction of that of excises and concluding that on the very restrictive assumptions of such a theoretical analysis, the income-tax burden may conceivably come out at around 25 per cent or more of the excise burden. Pragmatically the difference is large because some of the restrictive assumptions of such models need to be relaxed and the final appraisal is much hazier if one feels uncertain whether the "hypothesis of the negligible fraction" or, say, the " 25 per cent hypothesis" is the correct point of departure on the initial restrictive assumptions.

As I see it, the needed relaxations are connected mainly with the following circumstances. In the first place, many of the loopholes of direct taxation are practically inevitable, and some of the important loopholes create the same kind of additional welfare costs as highly selective excises. Harberger rightly emphasizes his objections to the differential burdens imposed by our direct taxes on alternative types of investments. The actual situation could no doubt be improved, but by Harberger's standards it would still be very bad. To take one example, the preferential treatment of capital gains is an almost inevitable feature of direct taxation, and it is also almost inevitable that many individuals who essentially earn incomes in the ordinary sense should be able to ride on the coattails of those deserving the capital-gains treatment, provided these recipients of ordinary income have invested in certain channels rather than in others. Over and above the theoretically recognized welfare cost of the direct taxes, these taxes inevitably introduce various "excise-like" distortions, which are substantial. One could, for example, 
place the investment projects of any period into a great many categories according to the investors' ability to turn various proportions of the yield into capital gains, and one would have to conclude that each of these categories is associated with a different effective tax rate!

Secondly, we should remember that the desire to promote growth does not stem entirely from superstition. To be sure, the case for growth rests in part on considerations of a political kind which it would be difficult to incorporate into an analytical model. I have in mind the relatively greater ease with which funds can be raised for high-priority public expenditures, including defense, if the tax revenue increases at given tax rates than if tax rates would have to be increased. But the case for growth rests in part also on the stimulus which the search for new knowledge (including basic research) receives from industrial innovation. We are faced here with a two-way relationship: not only does new knowledge lead to industrial innovation but industrial innovation, which undoubtedly requires capital formation, also leads to further acquisition of basic knowledge. The acquisition of new knowledge is frequently associated with favorable external effects (external to the investor who in a sense turns a semifinished invention into a finished one). Thus if the taxpayer needs to be pushed around, we may in some cases prefer to push him in the direction of saving even if, in terms of Harberger's application of the Pareto criteria, we hurt him somewhat more than we would by the taxes which push him away from saving.

Let me summarize. I suggest that it makes an appreciable difference whether we do or do not substitute other reasonable numerical guesses for Harberger's. If we engage in such substitutions, the result will be that, even on the simplifying assumptions implied in this type of analysis, the welfare cost of direct taxes ceases to be a "negligible fraction" of that of excises. In this case, the final appraisal depends to a large extent on how much weight we attribute to factors that are disregarded in the initial simplified models. When account is taken of such additional considerations, even the strongest initial conclusions become shaky, and weaker initial conclusions become all the shakier.

As to my own general appraisal, I will say that Harberger's paper has strengthened my conviction that the economist's argument for direct taxes cannot be brushed aside. However, I continue to be inclined to the view that no unqualified argument can be made for the superiority of the practically feasible kinds of direct taxation, and it does seem to me that in the postwar era the direct-indirect mix of our tax structure has been slanted too strongly toward direct taxation. At its practical 
best, each type of taxation involves its special kind of "inefficiency" (pushing-around effect), and also its special kind of "inequity." These various kinds of inevitable inefficiency and inequity need to be mixed with a view to the general policy objectives of a country in each period of its development. 